\title{
Phencyclidine Discoordinates Hippocampal Network Activity But Not Place Fields
}

\author{
Hsin-Yi Kao, ${ }^{1,2,5}$ Dino Dvořák, ${ }^{2,4,5}$ —EunHye Park, ${ }^{5}$ Jana Kenney, ${ }^{7}$ Eduard Kelemen, ${ }^{1,2,8}$ and $\oplus^{\circledR A n d r e ́ ~ A . ~ F e n t o n ~}{ }^{2,3,5,6}$ \\ ${ }^{1}$ Graduate Program in Neural and Behavioral Science, State University of New York, Downstate Medical Center, ${ }^{2}$ Department of Physiology and \\ Pharmacology, State University of New York, Downstate Medical Center, ${ }^{3}$ The Robert F. Furchgott Center for Neural and Behavioral Science, ${ }^{4}$ Joint \\ Graduate Program in Biomedical Engineering SUNY Downstate Medical Center and New York University/Polytechnic University, State University of New \\ York, Downstate Medical Center, Brooklyn, New York 11203, ${ }^{5}$ Center for Neural Science, New York University, New York, New York $10003,{ }^{6}$ Neuroscience \\ Institute, New York University Langone Health, New York, New York 10016, ${ }^{7}$ Institute of Physiology, Czech Academy of Sciences, Prague 14220, Czech \\ Republic, and ${ }^{8}$ National Institute of Mental Health, Klecany 25067, Czech Republic
}

We used the psychotomimetic phencyclidine (PCP) to investigate the relationships among cognitive behavior, coordinated neural network function, and information processing within the hippocampus place cell system. We report in rats that PCP (5 mg/kg, i.p.) impairs a well learned, hippocampus-dependent place avoidance behavior in rats that requires cognitive control even when PCP is injected directly into dorsal hippocampus. PCP increases 60-100 Hz medium-freguency gamma oscillations in hippocampus CA1 and these increases correlate with the cognitive impairment caused by systemic PCP administration. PCP discoordinates theta-modulated medium-frequency and slow gamma oscillations in CA1 LFPs such that medium-frequency gamma oscillations become more thetaorganized than slow gamma oscillations. CA1 place cell firing fields are preserved under PCP, but the drug discoordinates the subsecond temporal organization of discharge among place cells. This discoordination causes place cell ensemble representations of a familiar space to cease resembling pre-PCP representations despite preserved place fields. These findings point to the cognitive impairments caused by PCP arising from neural discoordination. PCP disrupts the timing of discharge with respect to the subsecond timescales of theta and gamma oscillations in the LFP. Because these oscillations arise from local inhibitory synaptic activity, these findings point to excitationinhibition discoordination as the root of PCP-induced cognitive impairment.

Key words: gamma; neural discoordination; NMDA antagonist; oscillations; place cell; theta

\section{Significance Statement}

Hippocampal neural discharge is temporally coordinated on timescales of theta and gamma oscillations in the LFP and the discharge of a subset of pyramidal neurons called "place cells" is spatially organized such that discharge is restricted to locations called a cell's "place field." Because this temporal coordination and spatial discharge organization is thought to represent spatial knowledge, we used the psychotomimetic phencyclidine (PCP) to disrupt cognitive behavior and assess the importance of neural coordination and place fields for spatial cognition. PCP impaired the judicious use of spatial information and discoordinated hippocampal discharge without disrupting firing fields. These findings dissociate place fields from spatial cognitive behavior and suggest that hippocampus discharge coordination is crucial to spatial cognition.

\section{Introduction}

Place cells are hippocampus principal cells that discharge in "place fields" that map discharge to locations, making place cell

\footnotetext{
Received March 7, 2017; revised Sept. 22, 2017; accepted 0ct. 17, 2017.

Author contributions: H.-Y.K. and A.A.F. designed research; H.-Y.K., E.P., and J.K. and performed research; A.A.F. contributed unpublished reagents/analytic tools; H.-Y.K., D.D., E.P., E.K., and A.A.F. analyzed data; H.-Y.K. and A.A.F. wrote the paper.

This work was supported by the National Institute of Mental Health-National Institutes of Health (Grants R21MH082417 and R01MH084038). We thank Steven E. Fox for comments on the manuscript.

The authors declare no competing financial interests.

H.-Y. Kao's present address: Center for Neural Science, New York University, New York, NY 10003.
}

studies de facto investigations of what information the hippocampus represents and how that information is represented (Friston and Buzsáki, 2016). Place field stability, although not absolute (Fenton et al., 2010; Ziv et al., 2013), is taken as crucial evidence

J. Kenney's present address: Institute of Organic Chemistry and Biochemistry, Czech Academy of Sciences, Prague, Czech Republic.

E. Kelemen's present address: National Institute of Mental Health, Klecany, Czech Republic.

Correspondence should be addressed to André A. Fenton, Center for Neural Science, New York University, 4 Washington Place, New York, NY 10003. E-mail: afenton@nyu.edu.

DOI:10.1523/JNEUROSCI.0630-17.2017

Copyright $\odot 2017$ the authors $\quad 0270-6474 / 17 / 3712031-19 \$ 15.00 / 0$ 
that hippocampus discharge represents spatial memory and acquired knowledge (Muller et al., 1987; Lever et al., 2002; Kentros et al., 2004; Wills et al., 2005).

The discharge of multiple place cells is temporally coordinated such that the likelihood that two cells will discharge in subsecond temporal proximity is characteristic for a cell pair (Dragoi and Buzsáki, 2006; Kelemen and Fenton, 2013). These temporal discharge patterns may themselves be crucial for place field firing and may in fact represent the information that animals use for spatial cognition (Buzsáki, 2010). Accordingly, manipulations that sufficiently disturb the temporal discharge relationships among cells, what is called "neural coordination," should also disturb place fields, and vice versa, and such manipulations should also disrupt spatial cognitive behavior. However, the "discoordination" hypothesis predicts that aberrant neural coordination and impaired cognition can associate with intact place fields. According to this hypothesis, cognitive deficits such as schizophreniarelated impaired cognitive control arise because processing multiple streams of information is corrupted by discoordination of neural activity in which cells that normally discharge together and cells that normally do not discharge together fail to maintain their appropriate timing relationships despite maintaining their individual response properties (Tononi and Edelman, 2000; Phillips and Silverstein, 2003; Uhlhaas and Singer, 2006; Lee et al., 2012; Lee et al., 2014; O'Reilly et al., 2014; Fenton, 2015).

The discoordination hypothesis derives from cell assembly (Hebb, 1949) and other ensemble hypotheses for how information is represented in the brain, which seem valid in hippocampus (Harris et al., 2003; Itskov et al., 2008; Fenton et al., 2010; Kelemen and Fenton, 2010; Park et al., 2011). Ensemble hypotheses assert that streams of information are represented by the coordinated temporal spiking relationships among cells in distributed representations. It follows that temporal discoordination will derange ensemble representations and the judicious use of information.

Here, we used a standard place cell paradigm with the psychotomimetic phencyclidine (PCP) to disturb cognition to evaluate the discoordination hypothesis by investigating the relationships among place fields, neural coordination, and spatial cognition (Fig. 1). PCP causes thought disorder in healthy people and exacerbates symptoms in schizophrenia patients (Cohen et al., 1962; Itil et al., 1967; Abi-Saab et al., 1998), but, despite a clear pharmacological mechanism of action, how PCP causes cognitive abnormalities is unknown. PCP is a potent uncompetitive antagonist of the glutamatergic $N$-methyl-D-aspartate receptor (NMDAR) with dopamine-mimetic effects at D2 and other receptors (Lodge and Anis, 1982; Anis et al., 1983). Although blocking NMDARs reduces excitation, it is unclear whether PCP's consequences arise from hypoglutaminergic or hyperglutaminergic effects (Adams and Moghaddam, 1998; Seeman et al., 2005; Sershen et al., 2008). Indeed, there is substantial evidence of network activation by PCP and other psychotomimetic NMDAR antagonists such as dizocilpine (MK801) and ketamine (Benardo, 1995; Grunze et al., 1996). These drugs increase the activity of prefrontal (Moghaddam et al.,
Place cell firing fields

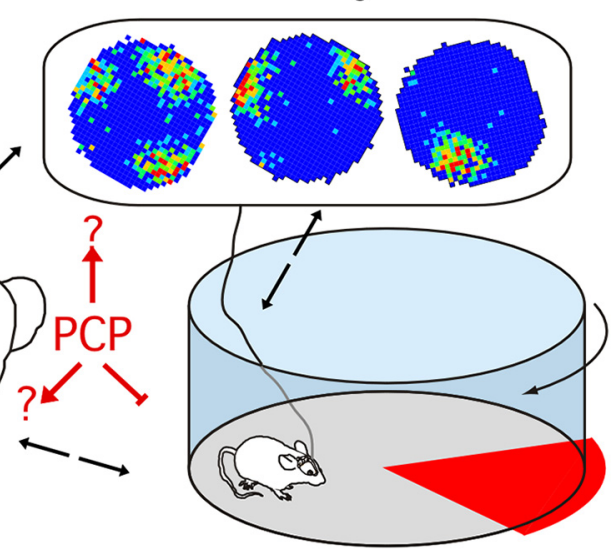

Cognitive control of behavior

Figure 1. Three levels of neurobiological function are assessed to examine widely held assumptions of their interrelatedness. Diverse prior work has assumed that neural coordination within the hippocampus circuit is crucial for generating place cell firing The neurobiological mechanisms at each level of analysis are assumed to feedback to affect the other levels. This pericit in the field, assumes that a manipulation to induce cognitive dysfunction manifest as impaired use of avoidance paradigm to assess hippocampus-dependent information processing and the hippocampus place cell paradigm to assess cognitive representations and coordinated hippocampus function.

1997) and cingulate (Breier et al., 1997; Vollenweider et al., 1997) cortical areas in human neuroimaging studies. In rats, MK801 decreases interneuron firing and increases pyramidal cell firing in prefrontal areas (Holcomb et al., 2005; Rowland et al., 2005) and disrupts the coupling of spiking to local gamma oscillations (Homayoun and Moghaddam, 2007), which is consistent with disinhibition effects. We stress that we used PCP neither to model schizophrenia nor to investigate a particular molecular component of hippocampus function, rather, we used it as a potent means of disrupting hippocampus-dependent cognitive function and investigating whether the drug also disrupts the single cell (firing fields) and ensemble (diverse neural coordination phenomena) discharge properties of the hippocampus.

\section{Materials and Methods}

All behavioral and electrophysiological methods have been described elsewhere and are described only briefly here.

\section{Animals}

All animals were maintained on a 12/12 light/dark cycle. Adult male Long-Evans rats were 2-3 months old during the experiments. All procedures conformed to institutional and National Institutes of Health guidelines for the ethical treatment of vertebrate animals and were approved by the State University of New York-Downstate and New York University Institutional Animal Care and Use Committees and the ethics committee of the Institute of Physiology, Czech Academy of Sciences, in accord with the directive of the European Community Council (86/609/ ECC).

\section{Drugs}

PCP, 1-(1-phenylcyclohexyl)piperidine hydrochloride, pH 7.4 SigmaAdrich) solutions were made fresh in sterile saline before use.

\section{Active place avoidance task}

Setup. An individual animal was placed on a metal $82-\mathrm{cm}$-diameter diskshaped arena (Figure $2 A$ ). The arena was elevated $76 \mathrm{~cm}$ above the floor and centered in a $3 \times 4 \mathrm{~m}^{2}$ room surrounded by opaque curtains and various items. The animal was constrained to remain on the disk by a 

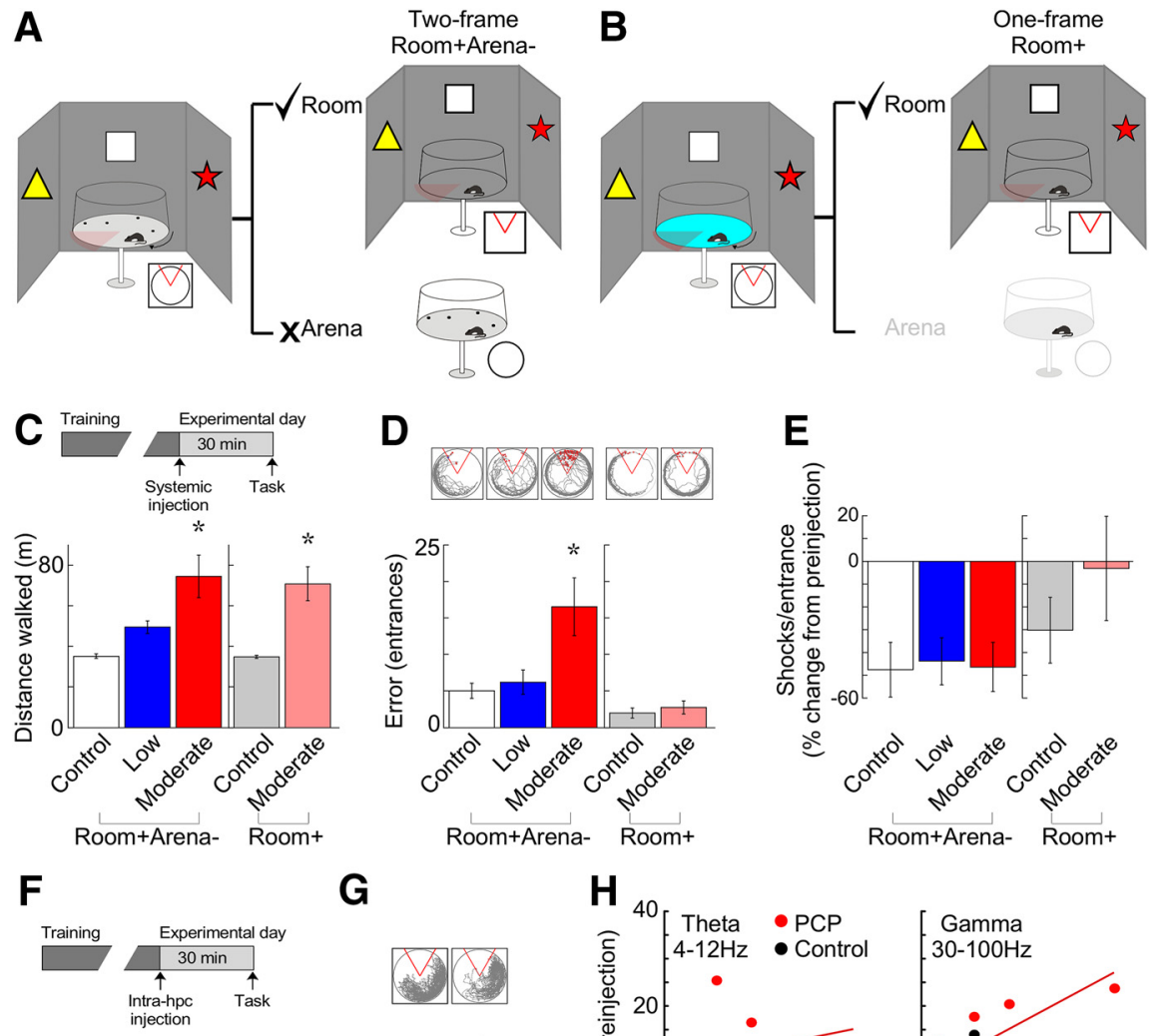

G
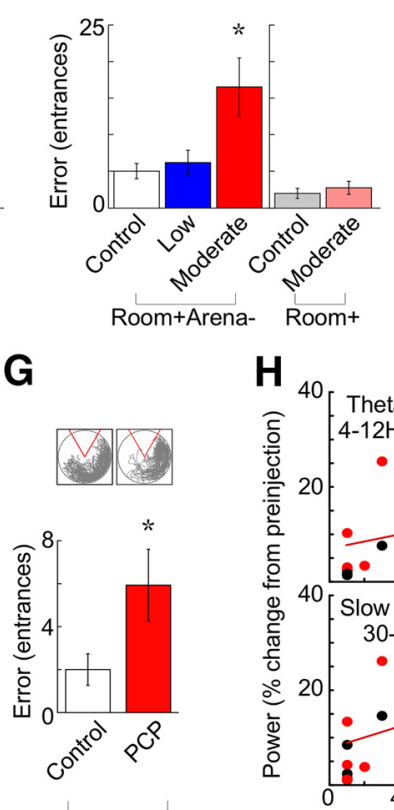

Room+Arena-

Room+Arena-

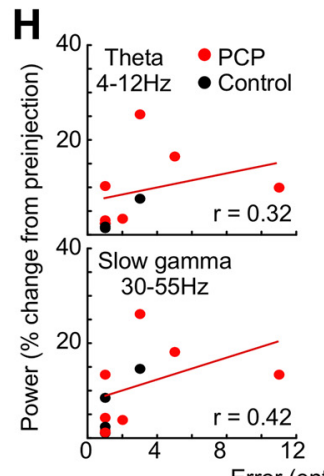

Figure 2. $\quad P C P$ impairs cognitive control. Shown are the schematics of the active place avoidance tasks on a continuously rotating arena that creates two distinct frames of spatial information, one defined by stationary room cues and another defined by rotating arena cues. $\boldsymbol{A}$, In the two-frame, Room + Arena - task variant, the rat must avoid a stationary shock zone (red) by using $(\boldsymbol{L})$ the stream of relevant "Room" information from the stationary frame while ignoring $(X)$ the stream of irrelevant "Arena" information from the rotating frame. Using one class of information while ignoring another requires cognitive control. $\boldsymbol{B}$, In the one-frame, Room + task variant, the irrelevant Arena information can be minimized by shallow water to attenuate the arena cues for place localization and reduce the demand for cognitive control. C, Inset, Experimental design. Rats were trained for several days on one task variant. After optimal performance, the rats received systemic administration of either a control or PCP dose 30 min before testing. The moderate dose of PCP causes hyperlocomotion, as measured by the distance that rat walked during both task variants. $\boldsymbol{D}$, Inset, Representative paths from a single rat; red indicates the shock zone and shocks. The moderate dose of $P C P$ impairs familiar two-frame $(n=10)$, but not one-frame $(n=4)$ place avoidance, as measured by the number of errors and entrances to the shock zone. $\boldsymbol{E}, P C P$ did not change responses to shock, measured as the change from the initial experience of shock before $P C P$ treatment. The number of shocks/entrance estimates the rat's willingness to escape shock. $F$, Infusing PCP into both hippocampi. Inset, Experimental design, $n=11$. Intrahippocampal PCP does not cause hyperlocomotion. $\mathbf{G}$, The injection but is sufficient to impair familiar two-frame Room + Arena - place avoidance. Inset, Representative paths from a single rat. $\boldsymbol{H}$, Room + Arena - avoidance deficit after intrahippocampal infusion was related to the magnitude of the change in mediumfrequency gamma oscillation amplitude in the hippocampal LFP, but not the changes in theta or slow gamma oscillation amplitudes $(n=8)$. Correlations and regression lines are for fits only to the PCP data. Error bars indicate \pm SEM. Control, low, moderate, $0,3,5 \mathrm{mg} / \mathrm{kg} P C P$ doses, respectively. ${ }^{*} p<0.05$ relative to all groups. Bold type indicates significant correlations.

40-cm-high transparent wall that allowed the animal to see the surrounding room through the wall. The position of the animal was tracked every $17 \mathrm{~ms}$ from an overhead camera using digital video spot tracking software (Tracker; Bio-Signal Group).

Both a two-frame Room + Arena - task variant (Fig. $2 A$ ) and a oneframe Room + task variant (Fig. $2 B$ ) were used. In both tasks, the arena rotated at $1 \mathrm{rpm}$ and an unmarked $60^{\circ}$ shock zone was fixed in stationary

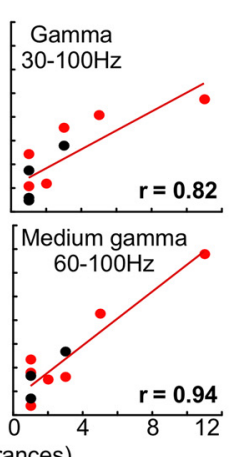

room coordinates. To avoid shock, the animal had to use the relevant stationary distal room cues to localize itself and the positions of shock. Because the arena was rotating, the animal also had to ignore the irrelevant information from the rotating spatial frame. In the Room + Arenatask variant, the irrelevant cues were scents and fecal boli that were stable on the arena surface, but in the Room + variant, their salience was reduced by shallow water $(\sim 2 \mathrm{~cm}$ saline) on the arena surface (Wesierska et al., 2005). Therefore, in the Room + Arena - task variant, the demand for cognitive control to ignore the salient irrelevant arena cues was high but the demand was low in the Room + task. All other cognitive and motivational aspects of the two tasks were similar. Avoidance was reinforced by a constant current foot-shock $(0.3 \mathrm{~mA}, 50$ or $60 \mathrm{~Hz}, 500 \mathrm{~ms}$ ). The shock was delivered across the rat on the grounded arena surface via a low impedance stainless steel shock electrode that was implanted subcutaneously between the rat's shoulders so the major voltage drop was across the rat's paws. Under control of software, shock was delivered when the animal was in the shock zone for 500 ms. The shock was repeated every $1.5 \mathrm{~s}$ until the animal left the shock zone. The spatial resolution of the position measurements was $\sim 3 \mathrm{~mm}$.

Behavioral protocol. The goal was to test the effect of PCP on active place avoidance after the task had been learned and the memories established. Rats were first habituated to the environment during a $10 \mathrm{~min}$ trial on the stationary arena with no shock. The shock and arena rotation were then turned on and rats were given $510 \mathrm{~min}$ training trials with $10 \mathrm{~min}$ intertrial interval. The 5 trials/d training protocol continued on subsequent days until the rat's performance reached a criterion number of shock zone entries, which was $\leq 2$ in 2 consecutive trials. The day after reaching criterion, each rat received a dose of PCP by either systemic injection or intrahippocampal infusion $30 \mathrm{~min}$ before testing in conditions that were identical to the training. The rats had a washout period of at least $48 \mathrm{~h}$ between different doses of PCP.

The time series of the animal's positions was analyzed. The distance that the animals walked was used to quantify locomotion. This measure increased after systemic PCP administration because the drug causes hyperlocomotion. The number of entrances into the shock zone was counted to estimate place avoidance. This measure decreases as the animals learn to avoid shock and can be interpreted as an index of the ability to perform the conditioned avoidance and judicious retrieval of the place avoidance memory in both task variants (Wesierska et al., 2005; Lee et al., 2012). To estimate the animal's willingness to escape shock under PCP, we measured the number of shocks that were received each time the shock zone was entered. Because this measure depends on the subject's prior experience with shock, we computed the difference in the shocks/entrance during the PCP trial compared with the initial trial before any experience with shock and PCP. In addition to comparing the measure of place avoidance in the high and low cognitive control task variants, this analysis of shocks/entrance served as addi- 
tional evidence for evaluating whether PCP impaired place avoidance per se or merely the willingness to avoid shock itself.

\section{Intrahippocampal infusion: surgical preparation and infusion protocol}

Rats were prepared for intrahippocampal infusions according to previously published methods (Wesierska et al., 2005; Pastalkova et al., 2006). Briefly, under Nembutal anesthesia $(50 \mathrm{mg} / \mathrm{kg})$, a pair of $22 \mathrm{Ga}$ guide cannulae were implanted stereotaxically and secured by dental cement above the dorsal hippocampal injection targets (AP: $-4.0 \mathrm{~mm}, \mathrm{ML}: \pm 2.5$ $\mathrm{mm}, \mathrm{DV}:-2.0 \mathrm{~mm}$ below the dura). Behavioral training began at least 1 week after surgery. PCP solution was infused at the hippocampal targets by pressure injection using a Hamilton syringe connected to a $30 \mathrm{Ga}$ needle by Tygon tubing. The rat was restrained by hand for infusions. One microliter of saline $(0.9 \%)$ or PCP $(6,8$, and $10 \mu \mathrm{g} / \mu \mathrm{l})$ was infused into each site for $2 \mathrm{~min}$. The needle was withdrawn $2 \mathrm{~min}$ after infusion ended. The rat was then returned to the home cage and observed for 30 min before testing.

\section{In vivo electrophysiology}

Acute recordings under anesthesia. The in vivo methods to record singleunit discharge from urethane-anesthetized rats have been described previously (Olypher et al., 2006). Briefly, rats were anesthetized with urethane $(1.2 \mathrm{~g} / \mathrm{kg}$, i.p.) and then mounted in a stereotaxic frame with precision micromanipulators (TSE Systems). The scalp was resected and two craniotomies were performed, one at AP $-3.8 \mathrm{~mm}$, ML $2.5 \mathrm{~mm}$ relative to bregma to provide electrode access to the dorsal hippocampus, and the other at AP $3.0 \mathrm{~mm}$, ML $0.5-0.7 \mathrm{~mm}$ to provide access to the medial prefrontal cortex. The dura was cut and tetrode-configured electrodes made from four twisted $25 \mu \mathrm{m}$ nichrome wires (impedance $50-$ $200 \mathrm{k} \Omega$ ) were lowered to the recording targets areas using the stereotaxic micromanipulators guided by electrophysiological landmarks in the LFPs and single-unit activity. The rest of the recording setup was the same as for the chronic recordings (see below). Data collection began once stable single unit ensemble activity could be isolated. A baseline recording was made for at least $30 \mathrm{~min}$ and then the rat received an intraperitoneal injection of the $5 \mathrm{mg} / \mathrm{kg}$ PCP or vehicle solution. Recordings continued at least $1 \mathrm{~h}$ after the injection.

Surgical preparation for chronic recordings. The in vivo electrophysiological methods have been described previously (Kelemen and Fenton, 2010). Briefly, tetrodes were made from four twisted $25 \mu \mathrm{m}$ nichrome wires (impedance $50-200 \mathrm{k} \Omega$ ). Eight tetrodes were assembled in a custom microdrive. The microdrive was implanted stereotaxically in rats under Nembutal anesthesia $(50 \mathrm{mg} / \mathrm{kg}$ ) and fixed to the skull with bone screws and dental cement. The tetrodes were aimed at a location above the left dorsal hippocampus (AP: $-4.0 \mathrm{~mm}$, ML: $-2.5 \mathrm{~mm}$, DV: -1.9 $\mathrm{mm}$ below the brain surface). At least 1 week after surgery, the tetrodes were gradually moved toward the hippocampus until action potentials from CA1 place cells could be recorded.

Recording setup. Extracellular single-unit activity was recorded from the rats using a cable that made electrical contact with the recording electrodes via a Millmax connector integrated into the electrode assembly. Extracellular, 2 ms tetrode action potential waveforms were buffered by a custom preamplifier, bandpass filtered (low-cut frequency 300 or $360 \mathrm{~Hz}$, hi-cut frequency 5-10 kHz), amplified (5000-10,000 times), and digitized ( 32 or $48 \mathrm{kHz}$ ). The digital signals were stored in real-time using either custom software (AcX; written by A.A.F.) or a commercial system (dacqUSB; Axona). LFPs were also acquired from an independently placed tetrode or $75 \mu \mathrm{m}$ nichrome electrode. Single-unit signals were referenced to this local electrode and LFP signals were referenced to an electrode that was targeted to the cerebellar white matter. The LFP signals were band-pass filtered $(0.1-300 \mathrm{~Hz}$ or $0.1-360 \mathrm{~Hz})$ and digitized at $2 \mathrm{kHz}$.

For recordings from awake, behaving rats, the electrophysiological data were recorded in parallel and synchronized with the rat's position on the arena.

Place cell recordings were made as the rats foraged on the arena for randomly scattered sugar pellets (Bio-serve). Once an ensemble of action potential spike trains from eight or more place cells could be recorded, an experiment began. The ensemble was recorded for at least $30 \mathrm{~min}$ as the rats foraged continuously in the preinjection session. The rat was returned to the home cage and provided with water for $10 \mathrm{~min}$ and then received an intraperitoneal injection of the control $0 \mathrm{mg} / \mathrm{kg}$, low $3 \mathrm{mg} / \mathrm{kg}$, or moderate $5 \mathrm{mg} / \mathrm{kg}$ dose of PCP before being returned to the arena. Postinjection recordings lasted $60 \mathrm{~min}$. All data were analyzed offline. The data recorded in the $30 \mathrm{~min}$ preinjection and the first $30 \mathrm{~min}$ postinjection intervals were analyzed for statistical comparisons.

LFP recording during foraging for scattered food. Power spectra were computed for the $30 \mathrm{~min}$ preinjection and the first $30 \mathrm{~min}$ postinjection recordings using MATLAB's Pwelch function (The MathWorks). The cross-frequency coupling was estimated between the phase of slowfrequency oscillations $(2-12 \mathrm{~Hz})$ and the amplitude of faster oscillations $(25-250 \mathrm{~Hz})$. We used the algorithm introduced by Canolty et al. (2006) with filters designed by MATLAB's Filter Design Toolbox (Dvorak and Fenton, 2014).

Phase-frequency discharge probability plots (see Fig. 7) were computed by convolving the LFP signal with a group of complex Morlet wavelets in the logarithmic range between 2 and $250 \mathrm{~Hz}$. Instantaneous phase of the band-specific LFP signals was obtained from the complex time series. The oscillation phase discharge probability was computed independently for each frequency band. The frequency-specific phase distribution of spiking was normalized by dividing the discharge distribution by the total number of action potentials in a given recording.

$L F P$ recording during place avoidance. Electrodes were made from 6 twisted $75 \mu \mathrm{m}$ nichrome wires (impedance $50-200 \mathrm{k} \Omega$ ) cut at an angle ( 1 $\mathrm{mm}$ between first and sixth wires) as in prior work (Radwan et al., 2016). The electrode was implanted stereotaxically in rats under Nembutal anesthesia $(50 \mathrm{mg} / \mathrm{kg}$ ) and fixed to the skull with bone screws and dental cement when the cannulae for intrahippocampal infusion were implanted (Kelemen and Fenton, 2010). The tip of the electrode was aimed in the left dorsal hippocampus CA1 (AP: $-4.0 \mathrm{~mm}, \mathrm{ML}:-2.5 \mathrm{~mm}, \mathrm{DV}$ : $-3.0 \mathrm{~mm}$ below the dura). The rats were tested in the behavioral task at least 1 week after surgery.

Power spectra were computed for the recordings of the last training trial and the first trial after PCP treatment using MATLAB's Pwelch function.

Single-unit identification. The action potentials emitted by different cells were discriminated offline using custom waveform parameter clustering software (Wclust; written by A.A.F.). Each action potential waveform was characterized by parameters that included the positive and negative peak voltages on each tetrode wire, the voltage at user-selected times relative to the spike onset, the waveform energy, principal components, and others. Single units were classified as those waveforms that formed distinctive clusters in the waveform parameter space according to objective criteria (Neymotin et al., 2011).

\section{Electrophysiological data analysis}

Classification of cell types. Single units were classified as complex spike or theta cells according to published criteria (Ranck, 1973; Fenton et al., 2008). Complex spike cells appear to be pyramidal cells, whereas theta cells are likely local interneurons (Fox and Ranck, 1975). Pyramidal cells were judged to have long-duration waveforms $(>250 \mu \mathrm{s})$, a low discharge rate $(<2$ action potentials/s) and a tendency to fire in bursts ( peak interspike interval $<10 \mathrm{~ms}$ ). Interneurons had short-duration waveforms $(<250 \mu \mathrm{s})$, a high discharge rate $(>2$ action potentials/s), and did not tend to fire in bursts.

Characterization of place cells. Cell-specific spatial firing rate maps were created for each cell by calculating the total number of spikes observed in each $2.5 \times 2.5 \mathrm{~cm}^{2}$ location divided by the total time the rat was observed in each corresponding location (examples are given in Fig. 1). Standard measures of spatial firing quality were then computed from each cell's firing rate map (Fenton et al., 2008). We report three of these measures: (1) the overall firing rate is the total spikes that a cell discharged divided by the total recording time; (2) the spatial coherence describes the local smoothness of the firing rate distribution (Muller and Kubie, 1989); and (3) the spatial information content describes the reduction in uncertainty about the rat's position given a particular firing rate (Skaggs et al., 1993). 


$$
\text { Information Content }=\sum_{x} p_{x} \cdot \frac{r_{x}}{R} \log _{2} \frac{r_{x}}{R}
$$

where $r_{\mathrm{x}}$ is the mean rate in pixel $x ; R$ is the overall mean rate; $p_{\mathrm{x}}$ is the probability of finding the rat in pixel $x$ and $p_{\mathrm{x}}=t_{\mathrm{x}} / T$ where $t_{\mathrm{x}}$ is the time spent in pixel $x$ and $T$ is the total recording time.

Single units were classified as place cells if the overall discharge rate was $0.1-2$ action potentials/s, the spatial coherence ( $z$ score) was $>0.4$, and the information content was $>0.4$ bits/spike. The spatial similarity, which describes how similar two firing rate maps are, was also computed as Pearson's correlation for the firing rates in corresponding pixels of the two maps.

Standardization of positional sampling. PCP is well known to cause hyperactivity and stereotypy in the movements of rodents, which could influence the quantitative measures of spatial firing quality (Muller et al., 1987). Accordingly, we standardized each place cell data time series to minimize positional sampling differences between recordings under the different doses of PCP. The goal was to make the standardized maps intermediate between a pretraining map and a PCP5 map. The algorithm began by computing the average time-in-position map from the first 15 min of all the preinjection recordings. Step 2 used the average preinjection time-in-position map to select randomly a subset of samples from the 30 min sessions in which the moderate dose of PCP was injected. The goal of this step was to downsample the PCP5 sessions and create the best approximations from the first $30 \mathrm{~min}$ of the PCP sessions to the average 15 min preinjection time map. These approximations were relatively poor. Therefore, the third step computed the average time map from the set of PCP5 time maps that were created in step 2. The final step used the average down-sampled PCP5 map to select samples randomly from all of the $30 \mathrm{~min}$ data time series. As a result, we selected data from each recording using the same algorithm so that the time-in-position maps were similar in all the recordings that we compared. These time-inposition maps accounted for a pseudorandom, unbiased $\sim 15$ min sample from throughout the $30 \mathrm{~min}$ recording. Examples of the average time-in-position maps for each type of session (preinjection, PCP0, PCP3, PCP5) are shown in Figure 5A. The measures of place cell quality were computed from the standardized recordings.

Overdispersion. The overdispersion in place cell discharge is computed as the variance of the standardized firing rates of the cell for passes through the firing field, as described previously (Fenton et al., 2010). The standardized firing rate $(z)$ was computed for each $5 \mathrm{~s}$ interval as follows:

$$
z=\frac{o b s-\exp }{\sqrt{\exp }}, \quad \exp =\sum_{i}^{5 s} r_{i} \times t_{i}
$$

where obs is the number of observed action potentials and $\exp$ is the number of action potentials that were expected according to the assumption of Poisson firing. The expectation is the sum of the products of the time spent $\left(t_{i}\right)$ in a location during time interval $i$ and the time-averaged rate at that location $\left(r_{i}\right)$ computed for all locations that were visited during the $5 \mathrm{~s}$. Note that, if the rat does not visit places where the cell fired during the entire recording, then $\exp =0$ and $z$ is undefined. To select intervals when the rat sampled a cell's firing field well, only those $5 \mathrm{~s}$ intervals were selected for the computation where exp was $\geq 5 \times$ the average rate for the cell; lower exp thresholds also led to the same conclusions.

Functional coupling of cell pairs. The functional coupling of spike trains from pairs of cells was estimated using Kendall's correlation (Press et al., 1993), which was computed as described previously (Olypher et al., 2006). The correlation was computed between the time series of spike counts from the two cells. The time series was generated by counting the number of spikes that the cell fired during each $250 \mathrm{~ms}$ interval.

Correlation of ensemble activity across time. The action potential discharge within an ensemble of $n$ cells during a particular time interval can be characterized by an activity vector of dimension $n$, which is just a list of spike counts that describes the number of spikes emitted by each cell during the interval (see example in Fig. 10B). The similarity of the ensemble's activity between two time intervals was calculated as Pearson's correlation of the two vectors. We computed the set of ensemble activity correlations between all pairs of $1 \mathrm{~min}$ time intervals during a recording. The set of correlations were organized and displayed as a correlation matrix (e.g., see Fig. 10B). Correlations during a range of time intervals were quantified by computing the average correlation in the corresponding region of interest of the matrix.

Estimating the ensemble activity due to changes in behavior. The ensemble activity correlations were changed dramatically by PCP injections (see Fig. 10F). The change could arise because PCP disturbed the temporal discharge relationships of the cells as predicted by the discoordination hypothesis or because PCP disturbed the rat's behavior such that the sampling of the environment was distinct in the preinjection and postinjection intervals. We evaluated this behavioral possibility by simulating ensemble spike trains on the basis of the preinjection firing rate maps and the rat's current behavior, as described previously (Fenton et al., 2010). The resulting Poisson spike trains were evaluated exactly like the raw data and results of analyzing the simulation and the real data were compared (see Fig. 11).

Decoding position from ensemble discharge. Estimates of the rat's location $(x)$ were computed from the single-unit ensemble activity vector $(n)$ using a published Bayesian algorithm (Zhang et al., 1998) in which the posterior probability of the current location is defined as $P(x \mid n)=$ $C(\tau, n) P(x)\left(\Pi_{i=1}^{N} f_{i}(x)^{n_{i}}\right) \exp \left(-\tau \Sigma_{i=1}^{N} f_{i}(x)\right)$, where $C(\tau, n)$ is a normalization factor so that $\Sigma_{x} P(x \mid n)=1, f_{i}(x)$ are firing rate maps for cells $i$... N obtained by binning the $2 \mathrm{D}$ space into $32 \times 322.5 \mathrm{~cm}$ bins, $P(x)$ is the time-in-location dwell distribution, $\tau$ is the length of the time window (300 ms), $n_{\mathrm{i}}$ is the number of spikes fired by the $i$-th cell in a given time window, and $x$ is the $(x, y)$ position of the rat. Intervals with no spikes were excluded from analysis. Centered posterior probability plots as in Figure 6 are computed by shifting the posterior probability such that the rat's observed location is at the center of the plot. To obtain the decoded location estimate, we selected the $10 \%$ of locations with the largest posterior probability and computed the probability-weighted average of their $x$ and $y$ coordinates. The decoding error was computed as the Euclidean distance between the observed and estimated locations. Confidence in the decoding was estimated as the "posterior confidence area," which is the area where the posterior is reliably elevated. The threshold was preset for asserting that the probability of locating the rat was elevated. The threshold was obtained independently in each preinjection recording as the locations with posterior probability greater than the mean \pm SD probability.

\section{Experimental design and statistical analysis}

Test statistics, the associated degrees of freedom (df), and $p$-values are reported. Analytical values are given to three significant digits. Statistical calculations were performed using JMP 12, MATLAB versions 8.5 and higher, and custom software written in C. Power analyses used GPower 3.0.6 (Franz Faul, Edgar Erdfelder, Albert-Georg Lang, and Axel Buchner).

Statistical design for analysis of the active place avoidance behavioral experiments can be found in the Results section describing Figure 2, $C-G$. Briefly, a within-subjects design was used to assess the effect of systemic PCP on behavior and hippocampus cell firing in the awake, freely behaving rat. Baseline measurements were made and then PCP and control solutions were administered in pseudorandom order with at least a $2 \mathrm{~d}$ wash-out period. This period was judged to be adequate because PCPinduced alterations could not be detected in neural activity or behavior beyond $1 \mathrm{~h}$ after treatment. Changes in behavior after the different treatments were compared.

Statistical design for analysis of the LFP electrophysiological recordings during the behavioral tests can be found in the Results section describing Figure $2 \mathrm{H}$.

Statistical design for analysis of the LFP electrophysiological recordings during foraging for scattered food that were examined for the changes in LFP power, phase-amplitude comodulation, and phase and amplitude features of gamma oscillations can be found in the Results section describing Figure 3.

Statistical design for analysis of the CA1 single-unit electrophysiological recordings during foraging for scattered food focused on the firing rate, spatial coherence, information content, map similarity, and proba- 
bility of firing during passes through the firing field. The design can be found in the Results section describing Figure 4. The design for analysis of these data after standardizing the position sampling can be found in the Results section describing Figure 5. Statistical design of the analysis of these data to assess accuracy and uncertainty of decoding the rat's position can be found in the Results section describing Figure 6.

The statistical design for the combined analysis of single-unit recordings and LFPs using their phase-frequency discharge preference during foraging for scattered food can found in the Results section describing Figure 7. The statistical design for analysis of these data to assess the discharge coordination of place cells can be found in the Results section describing Figure 8 and the statistical design for assessing the change of discharge coordination by evaluating pairs of simultaneously recorded place cells can be found in the Results section describing Figure $9 \mathrm{~A}$. Similarly, the statistical design for assessing the change of discharge coordination by evaluating pairs of simultaneously recorded single units during restriction to a small environment can be found in the Results section describing Figure $9 B$.

The statistical design for the electrophysiological single-unit recordings under anesthesia to assess the change of discharge coordination by evaluating pairs of simultaneously recorded single units can be found in the Results section describing Figure 9, $C-E$.

Statistical design to analyze the change of discharge coordination of place cells in the single-unit recordings from CA1 during foraging for scattered food can be found in the Results section describing Figure 10, $C-G$. The statistical design for analysis of the impact of spatial sampling on these analyses can be found in the Results section describing Figure 11.

Because neural activity parameters can vary strongly among cells and cell types, the comparisons of treatment effects on neural activity were computed relative to the baseline values of the particular cell. Assessing the effect of PCP on neural activity in the anesthetized rat was based on a between-subjects design. Each subject received either a PCP or control solution. Differences between treatments, categories of cell pair, or time intervals were compared by Student's $t$ test or one-way and multiple-way ANOVAs, as appropriate and as described in the Results. Analysis of within-subjects design data used paired $t$ test and repeated-measures ANOVA. When all pairwise post hoc comparisons were examined, Newman-Keuls post hoc comparisons were performed. Dunnett's test was used for post hoc comparisons against the control value. Statistical significance was accepted when $p<0.05$. All statistical comparisons of correlation values such as spatial similarity and coherence were performed on Fisher's $z$ transform of $r$ as follows:

$$
z=0.5 \cdot \ln \frac{(1+r)}{(1-r)}
$$

\section{Results \\ Cognitive behavioral impairment under PCP is indexed by excessive medium-frequency gamma oscillations}

Using the active place avoidance paradigm (Fig. $2 A$ ), we began by confirming that PCP impairs performance of a familiar spatial navigation task that requires cognitive control (Kelemen and Fenton, 2010, 2016). Animals on a continuously rotating diskshaped arena must use distal spatial cues to identify the location of a shock zone that is stable in the room. The rotation makes spatial information from the rotating disk irrelevant for avoiding the shock zone. This two-frame (Room+Arena-) variant of the task challenges the subject to use relevant spatial information from the room spatial frame and ignore the irrelevant information from the rotating arena spatial frame (Fenton et al., 1998; Fenton and Bures, 2003; Wesierska et al., 2005), which we have used to define cognitive control operationally in prior work that investigated directly whether place information about location in the room and in the arena are alternatively being represented in place cell spike trains during active place avoidance (Kelemen and Fenton, 2010). A separate one-frame (Room +) task variant was also tested. It requires avoidance of the same place in identi- cal conditions except that the arena surface is covered by shallow water to reduce the salience of arena cues that are irrelevant for avoiding shock (Fig. 2B). The shallow water reduces the demand for cognitive control to ignore the irrelevant arena information while using the relevant room information to avoid the constant current foot shock (Wesierska et al., 2005; Lee et al., 2012).

Well trained rats $(n=10)$ received a systemic injection of control ( $0 \mathrm{mg} / \mathrm{kg})$, low ( $3 \mathrm{mg} / \mathrm{kg})$, or moderate $(5 \mathrm{mg} / \mathrm{kg})$ doses of PCP 30 min before testing (Fig. 2C, inset). PCP caused the well known dose-dependent increase in locomotion (Fig. 2C, left; $F_{(2,27)}=9.94, p=5.82 \times 10^{-4}$, ANOVA, post hoc tests: control $=$ low $<$ moderate). However, only the moderate dose impaired the familiar two-frame active place avoidance measured by the number of entrances to the shock zone (Fig. $2 D$, left; $F_{(2,27)}=6.11, p=$ $6.47 \times 10^{-3}$, ANOVA, post hoc tests: control $=$ low $<$ moderate $)$. The impairment could be due to PCP reducing the sensitivity to shock, but this possibility is inconsistent with the observation that, when the rats entered the shock zone, they escaped even faster at all three PCP doses, as measured by the change in the average number of shocks that they received during each entrance (Fig. 2E, left; $F_{(2,26)}=0.03, p=0.970$, ANOVA; one trial had no entrances). These data suggest that PCP impairs the expression of a conditioned place avoidance memory and also induces hyperlocomotion.

Could the cognitive impairment be due to a PCP-induced disregard for the shock or inability to perceive the relevant stimuli or the concomitant hyperlocomotion, as we have shown in a different rat model? (O'Reilly et al., 2016). We observed that the moderate dose of PCP also induced hyperlocomotion in the Room + task variant (Fig. $2 C$, right; $n=4$ rats; $t_{(3)}=4.29, p=$ 0.023 , paired $t$ test) compared with control saline injections. However, PCP did not impair the same conditioned place avoidance in this task variant with low cognitive control demand (Fig. $2 D$, right; $t_{(3)}=0.67, p=0.551$, paired $t$ test). Again, PCP did not increase the number of shocks that were received once the rat entered the shock zone (Fig. $2 E$, right; $t_{(3)}=1.01, p=0.387$, paired $t$ test).

In a further effort to disentangle the hyperlocomotion effects of PCP from its potentially confounding effect on cognitive performance (Moghaddam and Adams, 1998), we tested whether intrahippocampal infusion of PCP is sufficient to reproduce the systemically induced impairment of familiar active place avoidance (Fig. $2 F$, inset). Compared with bilateral intrahippocampal saline infusions, PCP infusions of 6,8 , or $10 \mu \mathrm{g} / \mu \mathrm{l} / \mathrm{side}$ did not induce hyperlocomotion (Fig. $2 F ; t_{(22)}=1.89, p=0.072$, paired $t$ test). Nonetheless, PCP impaired place avoidance measured as an increased number of entrances (Fig. $2 G ; t_{(22)}=2.47, p=$ 0.022 , paired $t$ test). In the subset of eight rats from which we also recorded the hippocampal LFP, the magnitude of the PCPinduced performance deficit was significantly related to the magnitude of the change in CA1 medium-frequency gamma (60-100 $\mathrm{Hz}$ ) oscillation amplitude (Pearson's correlation coefficient $r=$ 0.94 , df $=6, p=1.63 \times 10^{-3}$ ), but not to the change in theta (Pearson's correlation coefficient $r=0.32, \mathrm{df}=6, p=0.484$ ) or slow gamma (Pearson's correlation coefficient $r=0.42$, $\mathrm{df}=6$, $p=0.348$ ) oscillation amplitudes (Fig. $2 H$ ). These findings demonstrate that PCP in dorsal hippocampus is sufficient to impair learned place responding in a task with significant cognitive control demand, although potentially confounding hyperlocomotion was absent. The findings also demonstrate that PCP-induced increases in hippocampus medium-frequency gamma oscillations predict the magnitude of the cognitive behavioral impairment, a novel finding that is predicted by the hypothesis that 
A

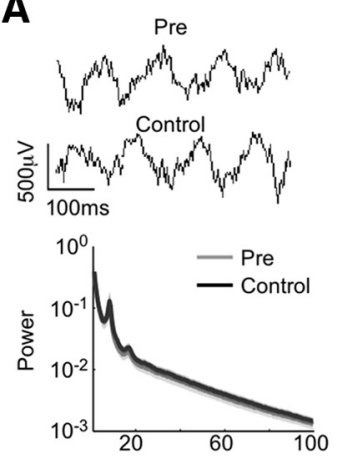

\section{B}
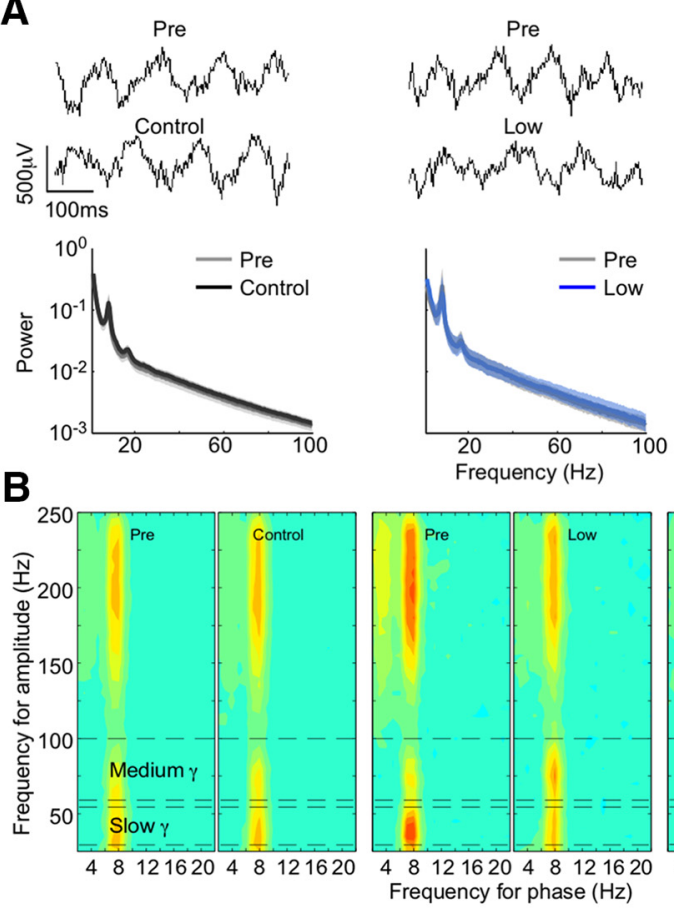

C

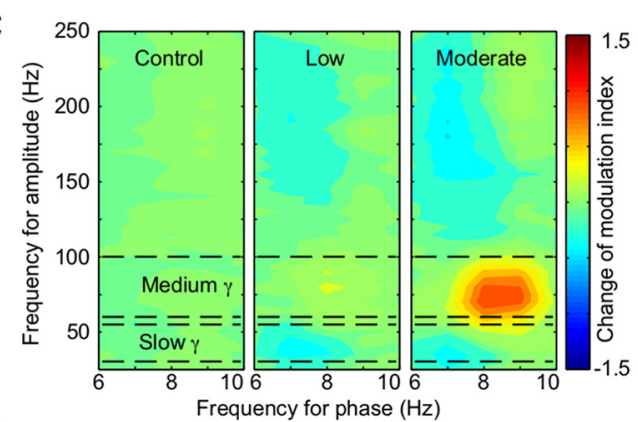

E

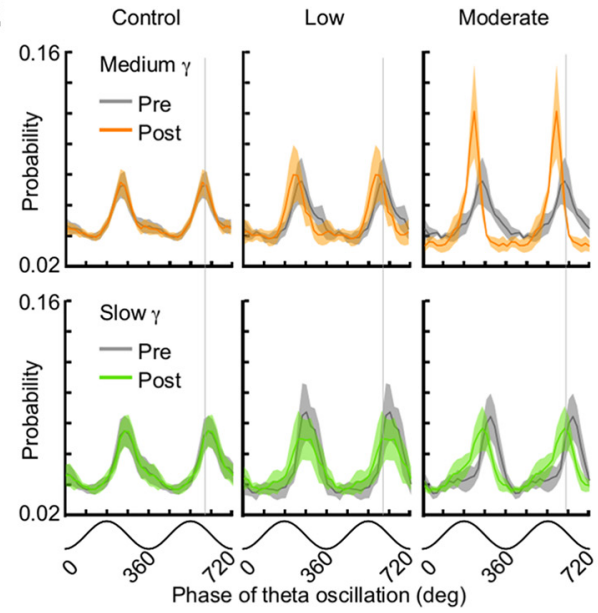

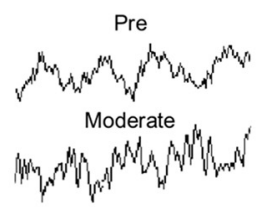
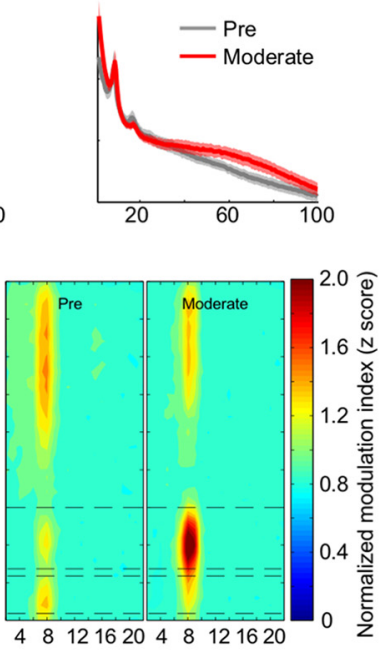

D Medium $\gamma$ - Slow $\gamma$

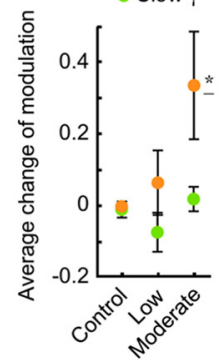

$\mathbf{F}$
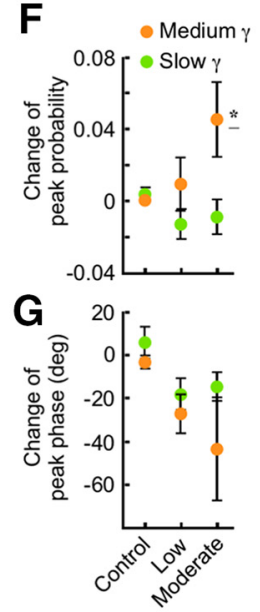

Figure 3. $P C P$ discoordinates CA1 LFPs. $\boldsymbol{A}$, Example LFPs at stratum pyramidale and the average power spectra from the $30 \mathrm{~min}$ before and after systemic PCP administration. Power is relative to the maximum of all six spectra. $\boldsymbol{B}, \boldsymbol{C}$, Pretreatment and posttreatment averaged cross-frequency coupling measured by comodulograms $(\boldsymbol{B})$ and the average posttreatment minus pretreatment difference comodulograms ( $\boldsymbol{C}$. The changes are quantified in $\boldsymbol{D}$ by average $P(P$-induced changes of cross-frequency coupling between theta and slow gamma $(30-55 \mathrm{~Hz})$, and theta and medium-frequency gamma $(60-100 \mathrm{~Hz}) 0$ oscillations. $\boldsymbol{E}$, Average theta-phase modulation profiles of slow and medium-frequency gamma oscillations (gray vertical lines indicate the phase at the peak of medium-frequency gamma before $P(P$ injection). Average effect of $P C P$ administration on the peak probability $(\boldsymbol{F})$ and phase $(\boldsymbol{G})$ of theta-modulated slow and medium-frequency gamma oscillations. Error bars and shading indicate \pm SEM. Pre, Preinjection; Post, postinjection; control, low, moderate, $0,3,5 \mathrm{mg} / \mathrm{kg}$ PCP doses and 12, 4, 5 recordings, respectively. ${ }_{-}^{*} p<0.05$ relative to all groups.

dominance of CA1 medium-frequency gamma over slow gamma, biases hippocampus output to process information currently available to the senses at the expense of what has been learned (Colgin et al., 2009; Fries, 2009; Keeley et al., 2017). All subsequent experiments examined the effects of systemic PCP administration.

\section{Aberrant LFP oscillations under PCP}

Next, we analyzed the effect of systemically administered PCP on the LFP at CA1 stratum pyramidale. These recordings were concurrent with the CA1 place cell recordings that we analyzed next. CA1 LFPs were reliably altered for $30 \mathrm{~min}$ after administering the moderate dose of PCP, so we compared LFPs during the $30 \mathrm{~min}$ before and after drug administration (Fig. $3 A)$. Only after the moderate PCP dose did CA1 gamma became exaggerated $\left(F_{(2,18)}=\right.$ $4.33, p=0.029$, ANOVA; Fig. $3 A)$. Delta oscillations $(1-4 \mathrm{~Hz})$ also increased $\left(F_{(2,18)}=\right.$ $10.64, p=9.68 \times 10^{-4}$, ANOVA $)$, but neither theta $\left(4-12 \mathrm{~Hz} ; F_{(2,18)}=2.03, p=\right.$ 0.160 , ANOVA) nor beta $\left(12-30 \mathrm{~Hz} ; F_{(2,18)}=\right.$ 1.21, $p=0.348$, ANOVA) oscillations changed (Fig. 3A).

We then investigated the coordination of theta and gamma oscillations, as has been reported in humans (Canolty et al., 2006), rats (Tort et al., 2009; Dvorak and Fenton, 2014), and mice (Radwan et al., 2016). Before PCP, theta-gamma phaseamplitude coupling was stronger for slow gamma $(30-55 \mathrm{~Hz})$ than for mediumfrequency gamma $(60-100 \mathrm{~Hz})$ oscillations. After the moderate PCP dose, the theta-phase modulation of medium-frequency gamma oscillations increased significantly without changing the modulation of slow gamma oscillations (Fig. $3 B-D)$. Both the slow and the mediumfrequency gamma oscillations occurred at the descending phase of the theta oscillations with medium leading slow (Fig. 3E). The moderate dose of PCP changed the medium-frequency gamma modulation in two ways without affecting the modulation of slow gamma (treatment $\times$ phase interaction: $F_{(2,36)}=4.47 ; p=0.019$, ANOVA; all post hoc comparisons with medium-frequency gamma after moderate PCP $p<0.01)$. In particular, the peak of the phase distribution increased after PCP administration (post hoc $p<0.05$; Fig. $3 F$ ) and increasing doses of PCP shifted the preference of the mediumfrequency gamma oscillations to earlier phases of theta $\left(F_{(2,18)}=3.6 ; p=0.048\right.$, ANOVA; Fig. $3 G$ ). Therefore, after the moderate dose of PCP, the preferred theta phase of medium-frequency gamma os- 
cillations became more phase specific with a preference for earlier phases, when pyramidal cell firing is normally less likely (Fox et al., 1986). PCP did not change the relationship between the theta-phase coupling of $100-250 \mathrm{~Hz}$ high-frequency oscillation amplitudes called the fast gamma or epsilon band (Belluscio et al., 2012), a component of which is the discharge afterpotential, making this an indirect estimate of the action potential discharge rate within the CA1 network (Schomburg et al., 2012; Dvorak and Fenton, 2014). Accordingly, the lack of a PCP effect on theta-coupled $100-250 \mathrm{~Hz}$ oscillations predicts that PCP has no systematic effect on place cell discharge rates.

Normal place field discharge properties of individual CA1 place cells under PCP We then investigated the effect of PCP on the spatial discharge of place cells $(n=$ 207; Fig. 4A) recorded from four rats before and after systemic administration of the control, low, and moderate doses of PCP. This provides a direct assay of how PCP affects a fundamentally cognitive variable, the neural representation of space. The average spatial discharge properties of place cells, specifically the firing rate $\left(F_{(3,203)}=1.60, p=0.191\right.$, ANOVA; Fig. $4 B)$, coherence $\left(F_{(3,203)}=1.79, p=\right.$ 0.150 , ANOVA; Fig. $4 C$ ), and information content $\left(F_{(3,203)}=0.67, p=0.571\right.$, ANOVA; Fig. $4 D$ ), were not different after the injections. The similarity of firing rate maps before and after injection was lower after the moderate dose of PCP than it was after the other doses $\left(F_{(2,96)}=13.86, p=\right.$ $5.15 \times 10^{-6}$, ANOVA; Fig. $4 E$ ), which was also reported for other NMDAR antagonists (Kentros et al., 1998; Ekstrom et al., 2001). However, this could be explained by the abnormal spatial sampling caused by PCP-induced hyperactivity and stereotypy (Fig. 2) because, when the data were standardized for more homogeneous sampling, the PCP-induced difference in firing field similarity was no longer apparent (Fig. 5, Table 1). Standardizing the spatial sampling caused the spatial coherence of firing fields to decrease after the moderate dose of PCP (Fig. 5C) and a general decrease in the information content except for the pretraining session (Fig. 5D), demonstrating the impact of spatial sampling on firing field characteristics (Muller et al., 1987; Maurer et al., 2005). We also examined the preinjection-postinjection differences of these discharge properties for individual cells. The absolute difference in each discharge property was higher after the moderate dose of PCP, indicating that this dose could modestly improve or degrade the spatial firing properties of individual place cells without causing a systematic change of
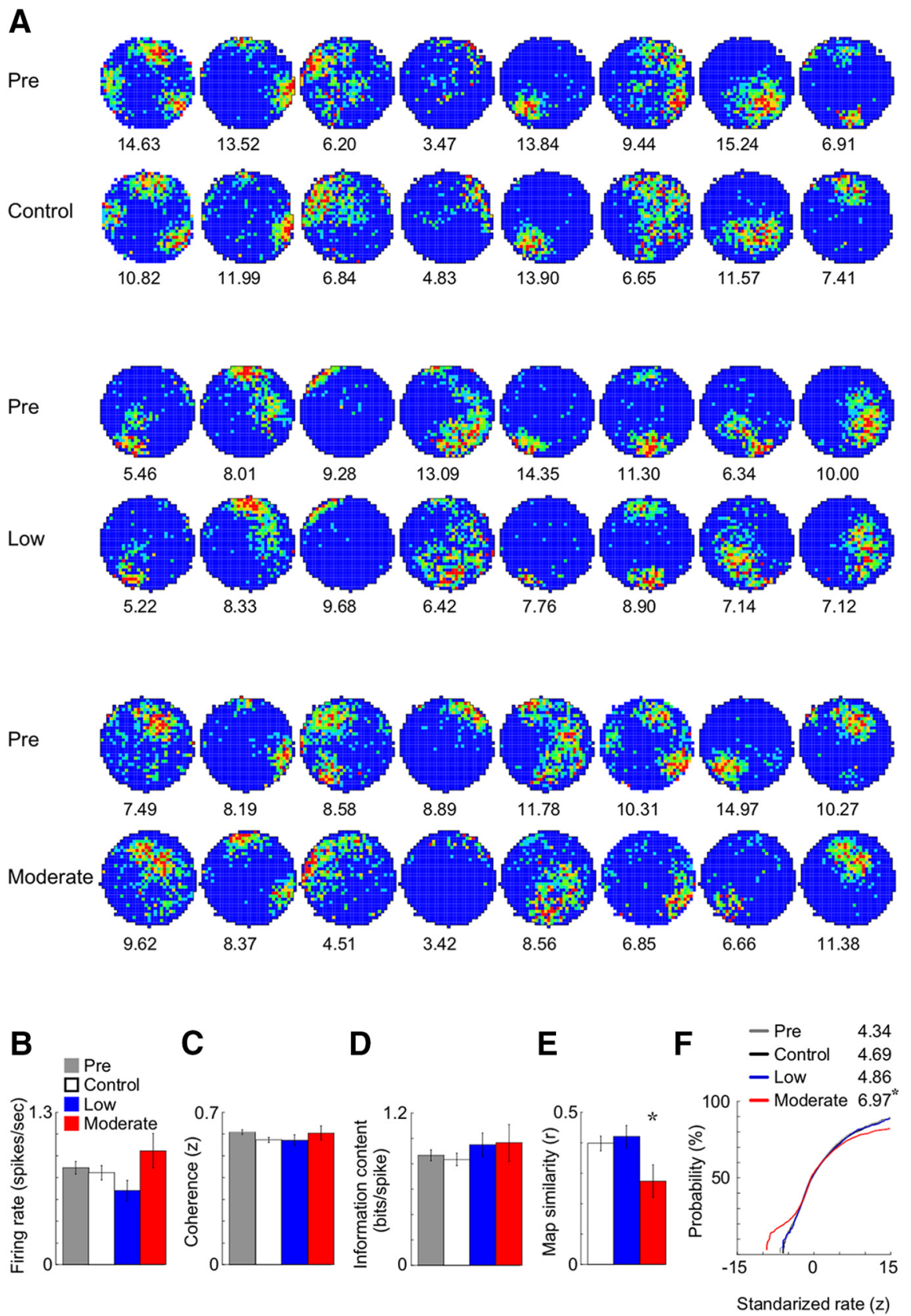

Figure 4. Place cell discharge properties are preserved after systemic PCP administration. $A$, Blue-to-red color-coded firing rate maps from eight example place cells recorded before and after control, low, and moderate doses of PCP. The median firing rate in the maximum rate (red) category is given below each map. Preinjection and postinjection measures of the quality of place cell discharge were unchanged by the $P C P$ injections: firing rate $(\boldsymbol{B})$; spatial coherence $(\boldsymbol{C})$; and spatial information content $(\boldsymbol{D})$. $\boldsymbol{E}$, Moderate dose of PCP affected the pre-post session similarity of the firing rate maps. $\boldsymbol{F}$, Moderate dose of PCP increased the overdispersion in place cell discharge. The plots are the cumulative probability distribution of standardized firing rates during $5 \mathrm{~s}$ episodes when the rat traversed a place cell's firing field. Overdispersion measured as the variance of the distribution is given. Error bars indicate \pm SEM. Comparisons were made by one-way ANOVA; Pre, Preinjection; control, low, moderate, 0, 3, $5 \mathrm{mg} / \mathrm{kg}$ PCP doses, respectively. Sixty-four place cells were recorded from 12 recordings in control, 26 from four recordings in low, and 17 from five recordings in moderate $\mathrm{PCP}$ dose. ${ }^{*} p<0.05$ relative to all groups.

the properties across the ensemble; PCP also did not alter the discharge properties of nonspatial presumptive pyramidal cells $(n=161)$ or alter firing rates in the small sample of presumptive interneurons that were recorded $(n=11$; Table 2). This overall preservation of place cell firing is consistent with reports that NMDAR antagonists do not disrupt place cell firing in familiar environments (Kentros et al., 1998; Ekstrom et al., 2001). 
A

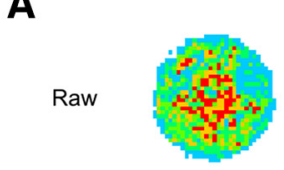

4.30

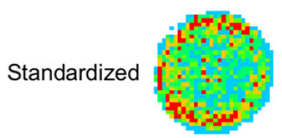

0.98

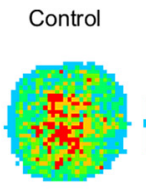

3.95

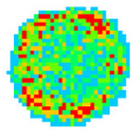

1.00

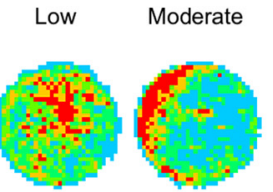

3.95

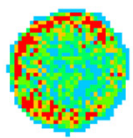

1.03
4.52

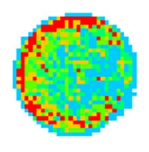

1.02

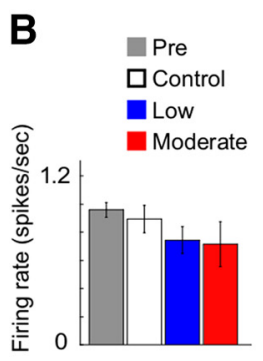

C
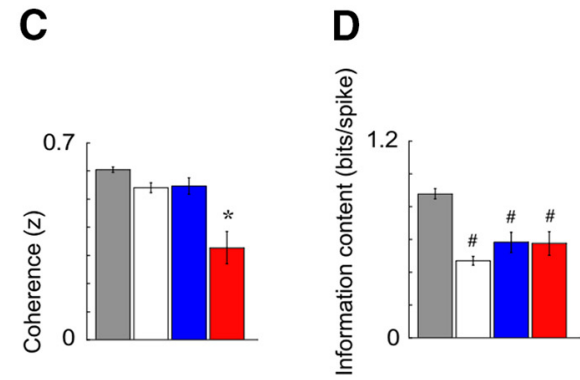

Figure 5. Standardization of position sampling. $\boldsymbol{A}$, Location-specific data for evaluating place cell firing were standardized to eliminate differences in spatial sampling caused by systemically administered PCP-induced movement stereotypy. Blue-to-red color-coded averaged time-in-location maps before (top row) and after (bottom row) standardization. After the moderate dose of $P C P$, the rat spent more time at the periphery of the arena due to the PCP-induced stereotypy. After standardized position sampling (bottom row), the postinjection time-in-location maps for each PCP dose were more similar than before standardization (top row). Preinjection and postinjection measures of the quality of place cell discharge after standardization were as follows: firing rate $\left(F_{(3,338)}=1.57, p=0.196 ; \boldsymbol{B}\right) ;$ spatial coherence $\left(F_{(3,338)}=23.98, p=4.29 \times 10^{-14} ; \boldsymbol{C}\right)$; spatial information content $\left(F_{(3,338)}=\right.$ $\left.24.67, p=1.85 \times 10^{-14} ; \boldsymbol{D}\right)$; and similarity of the firing rate maps $\left(F_{(2,132)}=1.99, p=0.141 ; \boldsymbol{E}\right)$. Error bars indicate $\pm S E M$. Comparisons were made by one-way ANOVA; Pre, Preinjection; control, low, moderate, $0,3,5 \mathrm{mg} / \mathrm{kg}$ PCP doses, respectively. ${ }^{*} p<$ 0.05 relative to all groups; $\# p<0.05$ relative to preinjection group.

Place fields were generally preserved under PCP, indicating spatial reliability, so we examined overdispersion, which estimates the temporal reliability of location-specific place cell discharge (Fenton and Muller, 1998; Olypher et al., 2002; Jackson and Redish, 2007). PCP increased overdispersion, which was greatest after the moderate dose $\left(F_{(2,169)}=3.51, p=0.032\right.$, ANOVA; Fig. $4 F$ ). Given that reduced overdispersion correlates with singularly focused spatial attention (Fenton et al., 2010), the overdispersion increase raises the possibility that PCP interferes with attention, a crucial component of cognitive control. Increased overdispersion also indicates that, despite preserved place fields moment-to-moment, the ensemble representation of space was excessively variable, suggesting degraded position representation in ensemble discharge.

\section{Impaired position representation under PCP}

We then assessed whether spatial information in place cell discharge is degraded after a moderate dose of PCP using a Bayesian algorithm to decode the rat's position from the momentary ( 300 ms) discharge of single-unit ensembles (Zhang et al., 1998). Only ensembles with at least 5 place cells (avg: $8.4 \pm 2.3$ cells) were examined. The average posterior probabilities appeared elevated over a larger area after the moderate PCP dose (Fig. 6A), suggesting greater inaccuracy. This was quantified by computing the decoding error as the distance between the decoded and observed locations (see example distributions in Fig. $6 B$, top) and then comparing the average decoding error before and after the various PCP injections (Fig. 6B, bottom). The average decoding error in the postinjection recordings were control $=20.6 \pm 3.6 \mathrm{~cm}$, low $=21.6 \pm 3.2 \mathrm{~cm}$, and moderate $=26.2 \pm 6.8 \mathrm{~cm}$ PCP doses,
E

which was significantly increased compared with the respective preinjection error after the moderate PCP dose $\left(F_{(2,12)}=\right.$ $4.2, p=0.041$, ANOVA; Dunnett's test: control $=$ low $<$ moderate). The confidence in the position decoding was also decreased by the moderate PCP dose, as estimated by the posterior confidence area, the region with elevated probability (Fig. 6C, top). Compared with the respective preinjection recordings, the effect of PCP dose was significant (Fig. $5 C$, bottom; $F_{(2,12)}=4.3, p=0.039$, ANOVA; Dunnett's test: control $=$ low $<$ moderate).

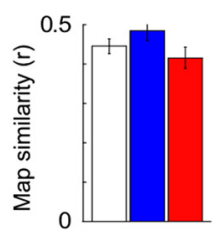

CA1 discharge changes in the LFP theta phase preference under PCP

We examined the relationships between the LFP and place cell discharge. Analysis of the frequency-specific phase at which cells discharge revealed cell-specific patterns of firing that were observed by plotting the probability of discharge within the temporal space defined by the phase and frequency of oscillations in the ongoing LFP (Fig. 7A). By inspection, the CA1 discharge is most strongly phase organized by theta-frequency oscillations, but the specific phase relationship varies across cells. Gamma-phase organization is less prominent (Fig. 7A). PCP changed this temporal organization of discharge $\left(F_{(2,160)}=\right.$ $3.1 ; p=0.048$, ANOVA; Fig. $7 B)$, specifically at theta frequencies. The 2-way ANOVA comparing the phase-frequency discharge probability plots before and after PCP administration in the theta, slow, and medium-frequency gamma ranges confirmed significant effects of PCP dose $\left(F_{(2,482)}=9.2\right.$; $p=1.20 \times 10^{-4}$, ANOVA $)$ and the frequency band $\left(F_{(2,482)}=\right.$ $3.3 ; p=0.038$, ANOVA), but not their interaction $\left(F_{(4,482)}=0.4\right.$; $p=0.809$, ANOVA). Post hoc tests confirmed that phase-frequency discharge probability changes from baseline were only caused by the moderate dose of PCP (Fig. 7B) and the effect was selective for theta band oscillations (Fig. 7C).

Next, we investigated whether PCP caused a uniform change in the phase-frequency discharge probability of the CAl cells or if it discoordinated the relationships that the network of place cells has to the LFP. This was estimated by computing the set of pairwise relationships between place cell firing and oscillations in the LFP. As shown in Figure 7D, the difference in the phase-frequency discharge probability profiles for a cell pair was similar before and after PCP injections (Pearson correlation coefficient $r$ range -0.303 to 0.889 , $\mathrm{df}=1998, p$ range 0.003 to $8.20 \times 10^{-680}$; Fig. $7 D$ ), but the change was greatest after the moderate dose of PCP, specifically in the theta band (Fig. 7E). The 2-way ANOVA confirmed a significant dose and band interaction $\left(F_{(4,1787)}=5.7 ; p=1.47 \times 10^{-4}\right.$, ANOVA $)$, as well as significant effects of dose $\left(F_{(2,1787)}=16.7 ; p=6.52 \times\right.$ $10^{-8}$, ANOVA $)$ and band $\left(F_{(2,1787)}=88.4 ; p=2.24 \mathrm{x}^{-37}\right.$, ANOVA). In addition to discoordinating oscillations in the LFP, these findings confirm that the moderate dose of PCP discoordinates the timing of CA1 place cell discharge with respect to the phase of theta oscillations. 
Table 1. Comparisons of CA1 place cell properties between raw and standardized data

\begin{tabular}{|c|c|c|c|c|}
\hline Original & $\begin{array}{l}\text { Pre } \\
(n=100)\end{array}$ & $\begin{array}{l}\text { Control } \\
(n=64)\end{array}$ & $\begin{array}{l}\text { Low } \\
(n=26)\end{array}$ & $\begin{array}{l}\text { Moderate } \\
(n=17)\end{array}$ \\
\hline \multicolumn{5}{|l|}{ Original } \\
\hline Firing rate (spikes/s) & $0.89 \pm 0.06$ & $0.84 \pm 0.07$ & $0.68 \pm 0.09$ & $1.05 \pm 0.16$ \\
\hline Spatial coherence (z) & $0.61 \pm 0.01$ & $0.57 \pm 0.01$ & $0.57 \pm 0.02$ & $0.61 \pm 0.03$ \\
\hline $\begin{array}{l}\text { Spatial information } \\
\text { content (bits/AP) }\end{array}$ & $0.87 \pm 0.04$ & $0.83 \pm 0.05$ & $0.95 \pm 0.09$ & $0.97 \pm 0.14$ \\
\hline \multirow[t]{2}{*}{ Map similarity $(r)$} & & $0.40 \pm 0.02$ & $0.42 \pm 0.04$ & $0.27 \pm 0.05^{*}$ \\
\hline & $\begin{array}{l}\text { Pre } \\
(n=171)\end{array}$ & $\begin{array}{l}\text { Control } \\
(n=82)\end{array}$ & $\begin{array}{l}\text { Low } \\
(n=39)\end{array}$ & $\begin{array}{l}\text { Moderate } \\
(n=50)\end{array}$ \\
\hline \multicolumn{5}{|l|}{ Standardized } \\
\hline Firing rate (spikes/s) & $0.96 \pm 0.05$ & $0.89 \pm 0.10$ & $0.74 \pm 0.10$ & $0.72 \pm 0.16$ \\
\hline Spatial coherence (z) & $0.61 \pm 0.01$ & $0.54 \pm 0.02$ & $0.55 \pm 0.03$ & $0.33 \pm 0.06^{*}$ \\
\hline $\begin{array}{l}\text { Spatial information } \\
\text { content (bits/spike) }\end{array}$ & $0.88 \pm 0.03$ & $0.47 \pm 0.03^{\#}$ & $0.58 \pm 0.06^{\#}$ & $0.58 \pm 0.07^{\#}$ \\
\hline Map similarity $(r)$ & & $0.45 \pm 0.02$ & $0.49 \pm 0.03$ & $0.42 \pm 0.03$ \\
\hline
\end{tabular}

After standardization, more cells meet the criteria to be classified as place cells. Data are shown as average \pm SEM. Significant effects were confirmed by one-way ANOVA.

${ }^{*} p<0.05$ relative to all groups, $\# p<0.05$ relative to control group.

Table 2. CA1 nonspatial pyramidal cell and interneuron firing rate

\begin{tabular}{|c|c|c|c|c|}
\hline & $\begin{array}{l}\text { Pre } \\
(n=79)\end{array}$ & $\begin{array}{l}\text { Control } \\
(n=48)\end{array}$ & $\begin{array}{l}\text { Low } \\
(n=15)\end{array}$ & $\begin{array}{l}\text { Moderate } \\
(n=19)\end{array}$ \\
\hline \multicolumn{5}{|c|}{ Nonspatial pyramidal cells } \\
\hline \multirow[t]{2}{*}{ Firing rate (spikes/s) } & $0.73 \pm 0.06$ & $0.75 \pm 0.08$ & $0.64 \pm 0.12$ & $0.73 \pm 0.12$ \\
\hline & $\begin{array}{l}\text { Pre } \\
(n=5)\end{array}$ & $\begin{array}{l}\text { Control } \\
(n=3)\end{array}$ & $\begin{array}{l}\text { Low } \\
(n=0)\end{array}$ & $\begin{array}{l}\text { Moderate } \\
(n=3)\end{array}$ \\
\hline \multicolumn{5}{|l|}{ Interneurons } \\
\hline Firing rate(spikes/s) & $12.43 \pm 3.33$ & $11.64 \pm 3.48$ & None & $6.48 \pm 1.26$ \\
\hline
\end{tabular}

\section{Discoordinated action potential discharge under PCP}

We investigated whether PCP discoordinates neural discharge among cells on the theta timescale of $250 \mathrm{~ms}$. Because the rats were typically moving $5.87 \pm 0.21 \mathrm{~cm} / \mathrm{s}$ and moved faster during the modest dose of PCP $(10.05 \pm 1.28 \mathrm{~cm} / \mathrm{s})$, during $250 \mathrm{~ms}$, they are mostly detected within a single $2.5 \times 2.5 \mathrm{~cm}$ location, which is the spatial resolution of the firing rate maps that we computed. This analysis measures neural coordination that can only weakly be affected by the increased movement of PCP-treated rats; they rarely changed the $\sim 6 \mathrm{~cm}^{2}$ analysis location during the $250 \mathrm{~ms}$ analysis interval (Olypher et al., 2003). Accordingly, compared with analyses that depend on averaging across longer time scales and position, this short-time scale, location-independent analysis is relatively insensitive to hyperlocomotion. The Kendall correlations of all simultaneously recorded cell pairs of place cells (Fig. 8) shows that the discharge of some cell pairs is positively correlated on the time scale of a few hundred milliseconds, whereas the discharge of other pairs is uncorrelated or negatively correlated (Olypher et al., 2006; Kelemen and Fenton, 2010; Kelemen and Fenton, 2013).

We next investigated whether PCP alters the coupling of discharge within the network of CA1 place cells. This was motivated by theoretical and empirical evidence that cognitive control is impaired by selectively increasing initially low correlations in ensemble action potential discharge (Wesierska et al., 2005; Olypher et al., 2006; Murray et al., 2014). MK-801, another NMDAR psychotomimetic, disrupts correlated firing in the prelimbic region of medial prefrontal cortex (Molina et al., 2014), as well as hip- pocampal CA1 ensembles recorded under urethane anesthesia (Szczurowska et al., 2018). Ketamine, another NMDAR psychotomimetic, also increases interregional cofluctuations of fMRI signals (Driesen et al., 2013). The stability of neural coordination was estimated by PCo, the Pearson correlation $(r)$ comparing cell pair coordination (measured as Kendall's $\tau$ ) between two 10 min epochs (Neymotin et al., 2017). Before injection, the coordination of cell pairs was stable across the three 10 min epochs (dose: $F_{(2,615)}=1.08, p=0.340$, ANOVA; epoch: $F_{(1,615)}=0.44, p=$ 0.507 , ANOVA; interaction: $F_{(2,615)}=1.40, p=0.247$, ANOVA; Fig. $8 A$ ). The moderate dose of PCP decreased the stability of the coordination, but the control and low doses did not change PCo $\left(\right.$ dose: $F_{(2,642)}=5.00, p=0.007$, ANOVA; epoch: $F_{(1,642)}=2.05$, $p=0.153$, ANOVA; interaction: $F_{(2,642)}=3.09, p=0.046$, ANOVA; significant post hoc comparisons: moderate preinjection $<$ moderate postinjection; control postinjection $<$ moderate postinjection; Fig. $8 B$ ). The coordination of cell pairs was stable after injection, but higher for the moderate dose (dose: $F_{(2,642)}=13.14, p=2.55 \times 10^{-5}$, ANOVA; epoch: $F_{(1,642)}=0.13$; $p=0.719$, ANOVA; interaction: $F_{(2,642)}=0.26, p=0.771$, ANOVA; Fig. $8 C$ ). To analyze the stability of coordination across the different preinjection and postinjection comparisons, the change of coordination between the early and late epochs was first normalized by the SD of the preinjection $\tau$ values (i.e., $\left[\tau_{\text {late }}-\tau_{\text {early }}\right] /$ $\left.\mathrm{SD}\left[\tau_{\text {early }}\right]\right)$. The moderate dose of PCP increased the coupling of cell pair discharge, but the control and low doses did not cause changes [dose: $F_{(2,963)}=2.32, p=0.099$, ANOVA; comparison (pre-pre, pre-post, post-post): $F_{(2,963)}=1.04, p=0.354$, ANOVA; Interaction: $F_{(4,963)}=4.67, p=9.76 \times 10^{-4}$, ANOVA; post hoc comparisons: the moderate PCP pre-post change is significantly different from all other changes, $p<0.03$; Fig. $8 D$ ].

Despite the robust findings of neural discoordination from analyses on subsecond timescales, we further investigated whether the findings arise from hyperlocomotion expressed on the seconds time scale resulting in the traversal of more firing fields. We first confirmed that, despite a dose-dependent effect on hyperlocomotion, only the moderate dose of PCP administration changed the spike train correlations among pairs of simultaneously recorded complex spike cells regardless of spatial firing quality and how close or far apart the firing fields were located (Fig. $9 A ; F_{(2,660)}=5.8, p=0.003$, ANOVA). We also recorded 11 CA1 complex spike cells in one additional rat that was restricted to a small, 24-cm-diameter enclosure, which minimized locomotor movements and therefore should have attenuated any effects that were consequences of PCP-induced hyperlocomotion (Fig. $9 B)$. The set of 53 cell pair correlations in this rat did not change significantly in the subset of cell pairs that were independent or positively correlated in the baseline recordings, but the moderate dose of PCP increased correlated discharge among cell pairs that were negatively correlated before drug administration (53 cell pairs, 2 pairs were extreme in baseline and excluded from analysis; effects of: PCP treatment $F_{(1,102)}=4.80, p=0.031$, ANOVA; baseline cell pair category $F_{(2,102)}=11.64, p=2.80 \times 10^{-4}$, ANOVA; interaction $F_{(2,102)}=6.24, p=2.78 \times 10^{-3}$, ANOVA). After PCP treatment, $2 / 3$ of negatively correlated cell pairs increased by more than 2 SDs, whereas only $3 / 53$ cell pairs changed in the independent and positively correlated categories (test of proportions $z=4.5, p=1.60 \times 10^{-5}$ ). This pattern of increased and maintained correlations has been observed under urethane anesthesia after disinhibiting the hippocampus by injecting tetrodotoxin into the contralateral hippocampus (Olypher et al., 2006). This is a manipulation in awake rats that impairs learning, consolidation, and recollection of the Room + Arena - active place avoid- 
A

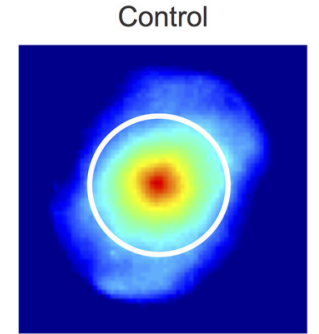

B
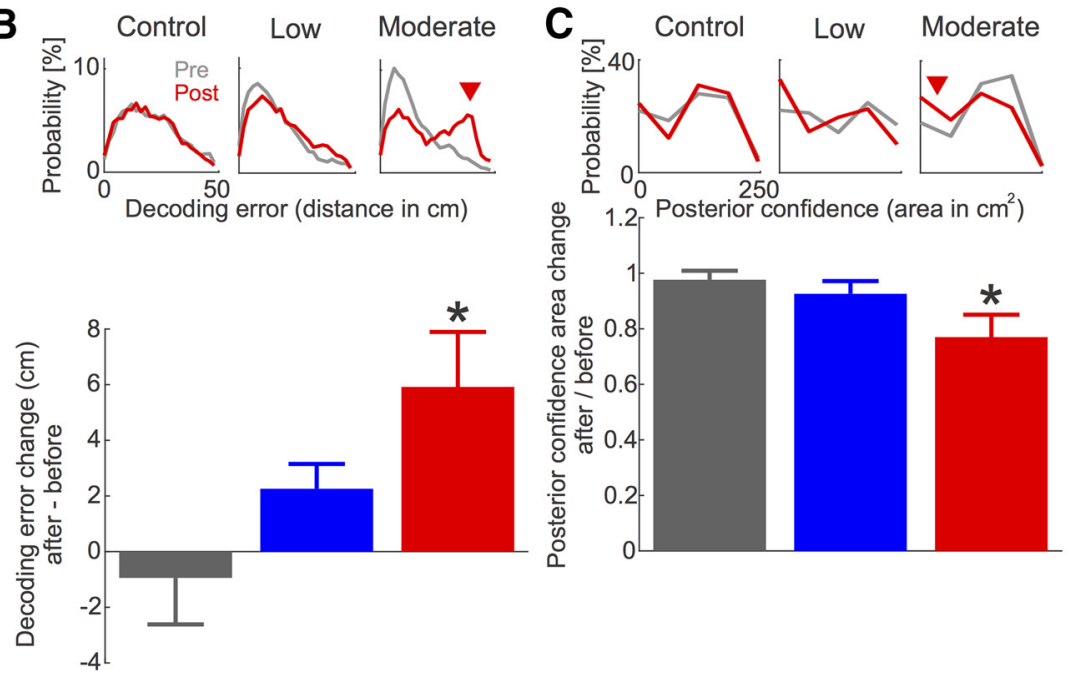

Figure 6. The moderate systemic dose of $P C P$ decreases the accuracy and increases the uncertainty of the rat's position decoded by Bayesian comparisons of postinjection ensemble discharge during $300 \mathrm{~ms}$ epochs to the probability of observing preinjection spatial ensemble discharge. $A$, Average decoded posterior probabilities centered at the rat's actual location for $0 \mathrm{mg} / \mathrm{kg}$ (control), $3 \mathrm{mg} / \mathrm{kg}$ (low), and $5 \mathrm{mg} / \mathrm{kg}$ (moderate) PCP doses. The white circle indicates the size of the circular arena. $\boldsymbol{B}$, Top, Example distributions of the decoding error for preinjection (gray) and postinjection (red) recordings showing both accurate decoding and increased decoding errors after the moderate PCP dose (red triangle). Bottom, Average decoding error for control (gray), low (blue), and moderate (red) PCP doses. C, Top, Examples distributions of the decoding uncertainty estimated by the elevated posterior area for preinjection (gray) and postinjection (red) recordings showing increased uncertainty after the moderate $P C P$ dose (red triangle). Bottom, Comparison of the average uncertainty of the decoding between preinjection and postinjection for control (gray), low (blue), and moderate (red) PCP doses. Error bars indicate \pm SEM. Comparisons were made by one-way ANOVA. ${ }^{*} p<0.05$ relative to control.

ance task variant with significant cognitive control demand, but not the Room + task variant with reduced cognitive control demand (Wesierska et al., 2005), resembling what we observed here with PCP (Fig. 2).

Finally, to completely rule out that these PCP-induced changes in neural coordination were a consequence of the PCP effect on locomotion, we investigated whether PCP administration also causes neural discoordination under urethane anesthesia (Fig. 9C). Similar to the findings in the awake rat, few cell pairs had initially negative correlations and, after PCP, their correlated discharge increased $(8 / 10$ by $>2$ SDs $)$ together with the independent cell pairs ( $15 / 23$ by $>2$ SDs). In contrast, there was no effect on cell pairs with initially positive correlations ( $4 / 47$ changed by $>2$ SDs; test of proportions $\left.z>8.1, p=2.26 \times 10^{-15}\right)$. The main effects and the interaction between PCP treatment and baseline cell pair category were significant (effect of PCP: $F_{(2,147)}=6.22$, $p=0.014$; effect of baseline category: $F_{(2,147)}=11.18, p=$ $3.021 \times 10^{-5}$; interaction: $F_{(2,147)}=4.23, p=0.016$, ANOVA). We also made these recordings from $\mathrm{mPFC}$, where, in contrast to hippocampus, almost all cell pairs had significantly positively correlated responses (113/127; Fig. 9D). After the moderate dose of PCP, 3/36 of the positively correlated cell pairs increased by $>2$ SDs, whereas all cell pairs increased their correlation if they were independent $(2 / 2)$ or negatively $(2 / 2)$ correlated before PCP. We observed positively, negatively, and independently coupled hippocampus-mPFC cell pairs $(n=250$; Fig. 9E). PCP selectively increased the correlation between the initially independent and negatively coupled cell pairs (effect of PCP $F_{(1,244)}=8.77, p=$ $3.37 \times 10^{-3}$, ANOVA; effect of baseline category $F_{(2,244)}=8.19, p=3.62 \times 10^{-4}$, ANOVA). Therefore, in both the dorsal hippocampal and mPFC networks, PCP preferentially increased the coactivation of cell pairs that were weakly coactive before PCP. Together, these data strongly support the view that the moderate dose of PCP changes neural coordination independently of behavior.

Because the increases in weak pairwise correlations is pathognomonic of strong changes in neural network states (Schneidman et al., 2006), we next examined the discharge pattern across the entire place cell ensemble as a function of recording time before and after PCP administration. In an example recording (Fig. $10 A$ ) before PCP administration, the ensemble activity pattern during each minute was similar to the pattern at each other minute (Fig. $10 B, C$ ), which was quantified by high, significant Pearson's correlation coefficients $(r \sim 0.7)$ of the ensemble activity vectors. The moderate dose of PCP radically changed this stationarity in the temporal structure of ensemble activity. By the first post-PCP minute, the ensemble pattern was uncorrelated (Pearson's correlation coefficient $r \sim 0.0$ ) with the preinjection pattern. The post-PCP ensemble pattern was at least as stationary as the preinjection pattern for $>20 \mathrm{~min}$. From about $25 \mathrm{~min}$ after PCP, the ensemble activity switched between the preinjection and postinjection patterns at intervals of several minutes (Fig. $10 B, C)$. The moderate dose of PCP consistently induced an aberrant pattern of ensemble discharge that did not correspond to the established representation. This abnormality was not observed after the control or the low doses of PCP (Fig. 10D-G; $F_{(2,1)}=11.93, p=5.03 \times 10^{-4}$, ANOVA). Although this secondsscale discoordination of ensemble neural discharge is predicted by the increased pairwise correlations at $250 \mathrm{~ms}$ resolution, it could not be explained by the PCP-induced changes of spatial behavior (Fig. 11). Therefore, the moderate dose of PCP discoordinated the temporal relationships between pairs and ensembles of cells, but the location-specific firing of individual place cells remained relatively undisturbed (Fig. 4).

Furthermore, the Figure $11 \mathrm{~A}$ correlation matrix suggests that CA1 activity is multistable and that PCP may simply change the likelihood of observing different ensemble activity states, rather than inducing a de novo activity pattern. In this example, during the baseline before PCP, the ensemble activity was transiently more like the PCP activity than the baseline activity. Such occasions are visible as moments of low correlation (yellow stripes) with the first $30 \mathrm{~min}$ of pre-PCP activity vectors and as moments 
A
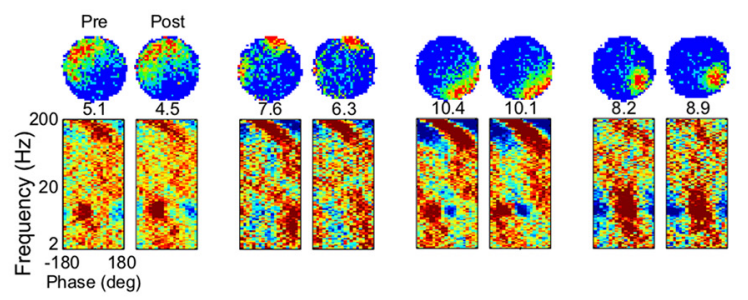

Low
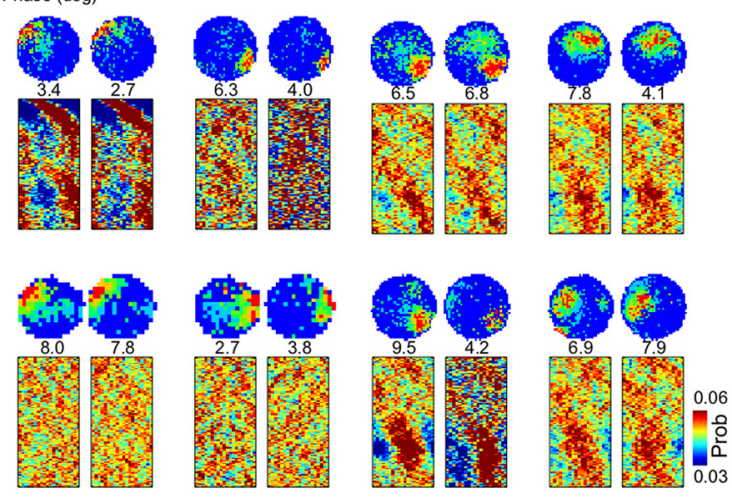

B

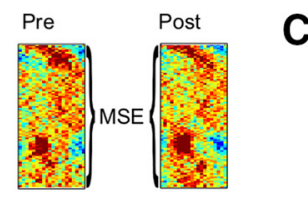

C
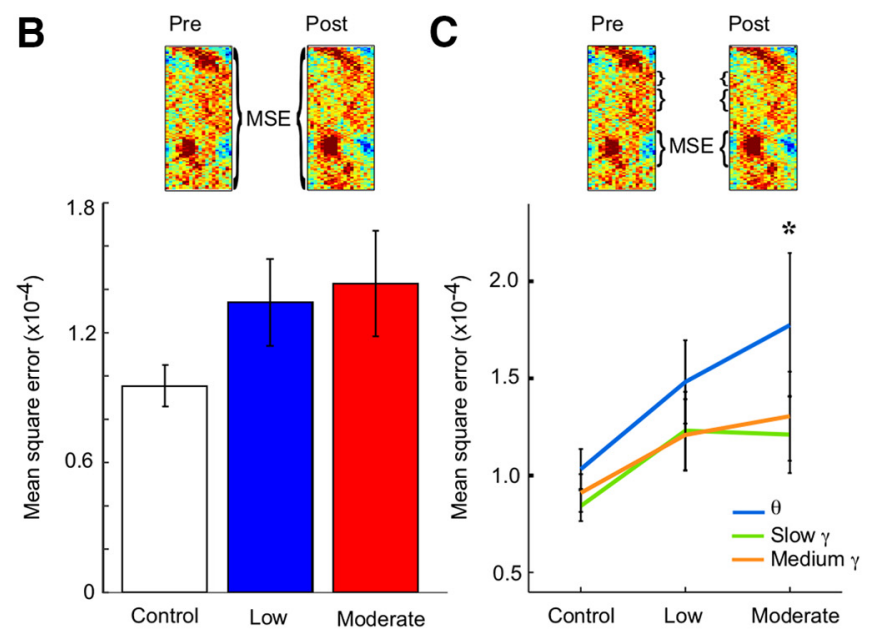
(
D

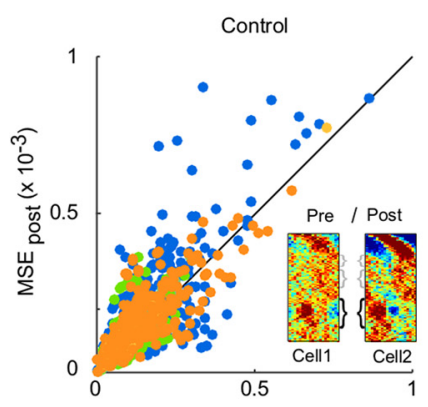

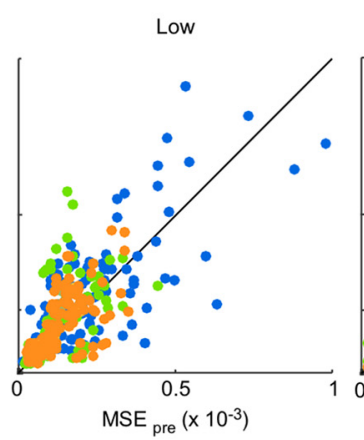

E

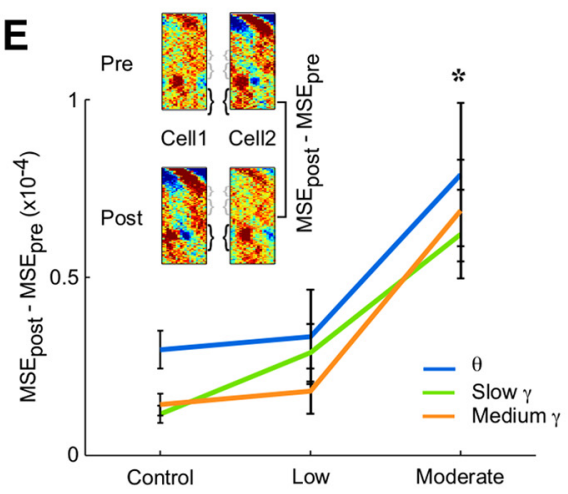

Figure 7. $P C P$ changes discharge phase-frequency preference of principal cells. $A$, Phase-frequency discharge probability plots for example place cells recorded before and after systemic PCP injection. Probability in the plot is indicated by color and the firing rate map of the cell is given above. Stability of wideband $(\boldsymbol{B})$ and band-specific $(\boldsymbol{C})$ phase-frequency discharge probability after $P C P$ treatment. $\boldsymbol{D}, \boldsymbol{E}, S$ catter plots $(\boldsymbol{D})$ and summary plots $(\boldsymbol{E})$ of the cell pair stability in the relationship between the individual phase-frequency discharge probability maps before and after PCP. Error bars indicate \pm SEM. Comparisons were made by ANOVA. Pre, Preinjection; Post, postinjection; control, low, moderate, 0, 3, 5 mg/kg PCP doses, respectively. Sixty-four place cells were recorded from 12 recordings in control, 26 from four recordings in low, and 17 from five recordings in moderate doses of $P C P$. * $p<0.05$ relative to control.

of high correlation (red stripes) with the $30 \mathrm{~min}$ of post-PCP activity vectors. Reminiscent of the preplay phenomenon (Dragoi and Tonegawa, 2011, 2013), this observation suggests that both the pre-PCP and post-PCP neural activity had been encoded in CA1 and that experiencing PCP merely increased the probability of expressing the preestablished post-PCP pattern.

\section{Discussion \\ Main findings}

We find that a moderate dose of PCP impairs spatial cognitive behavior that requires cognitive control (Fig. 2) and discoordinates the timing between distinct hippocampal CA1 signals with minimal disruption of place fields (Figs. 4, 5). The differences shown in Figure 4 and 5 in the quantitative measures of firing field quality and stability illustrate the impact of position sampling on these measures, as has been reported previously (Muller et al., 1987; Maurer et al., 2005). This discoordination was measured in multiple ways: (1) as an aberrant dominance of neocortical input-associated medium-frequency gamma oscillations over CA3 input-associated slow gamma oscillations (Fig. 3); (2) as a disorganization of spiking by theta oscillations (Fig. 7); and
(3) as a tendency of place cells that did not discharge together to increase subsecond coactive firing, which manifested as strengthened and unfamiliar hippocampal network states during behavior in a familiar environment (Figs. 8, 9, 10). This was also observed in hippocampus-mPFC investigations of neural coordination (Fig. 9). Despite the neural discoordination, PCP had minimal effects on the time-averaged spatial firing properties of individual place cells. This spatially accurate firing became more temporally unreliable under PCP on the time scale of the few seconds of crossing a firing field (Fig. $4 F$ ). Consistent with this temporal unreliability, decoding location from ensemble discharge on the $300 \mathrm{~ms}$ time scale was worse after the moderate dose of PCP (Fig. 6). These studies demonstrate that PCPinduced cognitive impairment and neural discoordination can be independent of psychotomimetic-induced hyperlocomotion, unlike most prior studies. Although the hyperlocomotion was general, the effects of PCP on cognitive behavior and neural activity were task specific (Fig. 2D), frequency band specific (Figs. $2 H, 3 B-D$ ), and neural coordination category specific (Figs. $7 C-E, 8)$. Furthermore, some forms of neural discoordination 
A
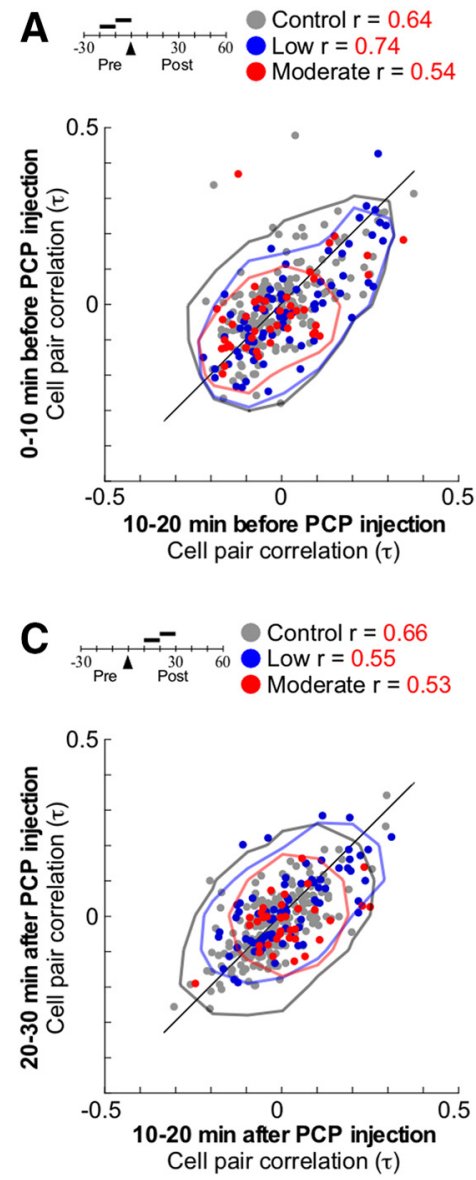
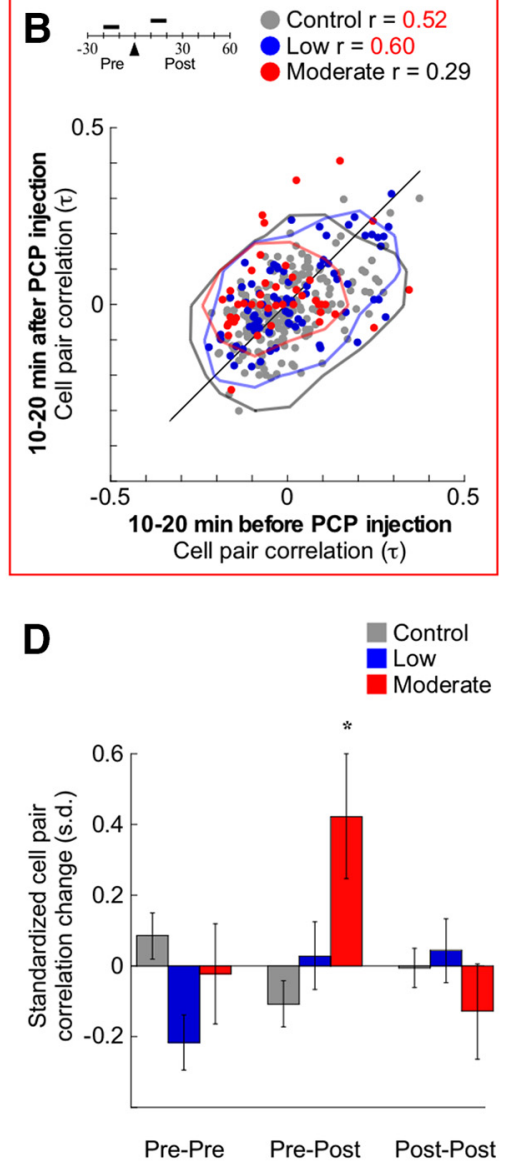

Figure 8. Systemic PCP-induced instability of subsecond timescale discharge coordination of place cells. Cell pair coordination was estimated by computing Kendall's correlation $(\tau)$ for all pairs of simultaneously recorded place cells. Spike counts were determined every $250 \mathrm{~ms}$ and the correlation was computed during $10 \mathrm{~min}$ epochs of the preinjection and postinjection recordings. Stability of the coordination is estimated by PCo (Neymotin et al., 2017), the Pearson correlation ( $r$ ) comparing cell pair coordination in two epochs for two preinjection epochs $(\boldsymbol{A})$; preinjection and postinjection epochs $(\boldsymbol{B})$; and two postinjection epochs $(\boldsymbol{C})$. The isodensity contours in $\boldsymbol{A}$ - $\boldsymbol{C}$ highlight the relative changes in cell pair coordination. $\boldsymbol{D}$, Change of coupling between the discharge of cell pairs in $\boldsymbol{A}-\boldsymbol{C}$ was normalized as follows: $\left(\tau_{\text {late }}-\tau_{\text {early }}\right) /$ SD [early]. A total of 206 place cell pairs were examined after the control dose, 75 pairs after the low dose, and 47 pairs after the moderate dose. Error bars indicate \pm SEM. Comparisons were made by ANOVA. Significant $(p<0.05)$ Pearson correlations are indicated by red. *Significantly different from all others.

could also be demonstrated under anesthesia (Fig. 9C-E) and at subsecond time scales, during which the spatial behavior was effectively constant during the window of analysis (Figs. 8, 9).

These findings suggest that memory storage itself was not disturbed by PCP and demonstrate stable hippocampus place fields during impaired hippocampus-dependent spatial cognition. The findings highlight that normal, stable place fields do not predict normal spatial competence. We observed instead that the dose of PCP that induces neural discoordination also impairs a familiar place avoidance task, but only if the demand for cognitive control is high (Fig. 2). This indicates that PCP-induced deficits are in the use of established spatial memories, rather than in place learning or information storage per se (Bannerman et al., 2012). Consistent with unimpaired Room + place avoidance under PCP, the rat's spatial competence recovers once the acute effects of $\mathrm{PCP}$ wear off. Furthermore, infusing PCP directly into dorsal hippocampus impairs familiar place avoidance and the magnitude of the impairment is indexed by the aberrant increase of mediumfrequency gamma oscillations (Fig. $2 \mathrm{H}$ ), demonstrating that the action of PCP in the hippocampus is sufficient to cause these cognitive consequences, but not the sensorimotor disturbances that accompany systemic PCP administration (Fig. 2C).

\section{Electrophysiological effects of PCP}

The impairing dose of PCP enhanced the theta-phase modulation of mediumfrequency gamma without changing the modulation of slow gamma. Mediumfrequency gamma in CA1 is associated with neocortical activity and slow gamma with memory-related CA3 input (Colgin et al., 2009; Bieri et al., 2014; Schomburg et al., 2014). Accordingly, the present findings suggest that PCP affects the likelihood of processing in the separate neocortical and hippocampal information streams. Such a PCP-induced imbalance may account for the inability to resolve conflicts between relevant and irrelevant spatial information in the Room+Arenatask variant even when the conditioned avoidance is familiar. The increase in gamma power that we observed replicates prior work showing that PCP (Ma and Leung, 2000) and other NMDAR antagonists increase gamma oscillations (Ehrlichman et al., 2009; Hong et al., 2010; Lazarewicz et al., 2010), as well as reports of altered theta-medium-frequency gamma cross-frequency coupling (Caixeta et al., 2013) (Fig. 3). The present observations extend these findings to destabilized cell-specific theta phase discharge probabilities (Fig. 7) and increased discharge coupling among initially weakly coupled cell pairs (Figs. 8, 9) to generate unfamiliar and strong network states (Fig. 10). The major effect of PCP is to discoordinate neural activity, an effect that has been reported under anesthesia with MK-801, a related drug, in hippocampus (Szczurowska et al., 2018) as well as mPFC (Molina et al., 2014). Preserved place cell spatial firing in familiar conditions after PCP (Fig. 4) is consistent with prior work using the competitive NMDAR antagonist CPP (Kentros et al., 1998; Ekstrom et al., 2001). However, the temporal organization of discharge among groups of CA1 cells was changed on multiple time scales ranging from 100's of milliseconds (Figs. 7, 8, 9) to minutes (Fig. 10). Preserved place cell firing after PCP is consistent with spared spatial memory and navigation after NMDAR antagonists (Morris et al., 1986; Bannerman et al., 1995; Saucier and Cain, 1995), whereas the discoordination of neural discharge predicted the PCPinduced impairment of cognitive control.

Finally, an unexpected observation suggested that PCP could merely increase the probability of expressing latent but unusual ensemble patterns of activity (Fig. 11A). This is intriguing because PCP induces hallucination (Cohen et al., 1962; Abi-Saab et al., 1998), but how might hallucination manifest in a rat? A mechanistic hypothesis for a neural correlate inspired by the observation shown in Figure 11A is that such unusual ensemble activity patterns are an alternative expression of the otherwise normal activity of individual place cells. Although substantial further work is required to investigate such a possibility and others, the place cell research paradigm may offer a means to investigate 
rigorously the potential relationship between such PCP-induced dynamics and hallucination (Hoffman, 1997; Hoffman and McGlashan, 2001). These electrophysiological findings highlight what has been called "the problem of the missing middle." Relatively little is known about how the well characterized molecular details of PCP's actions alter mesoscale neural network processes to produce the also relatively well characterized macroscale observables of behavior (Laughlin et al., 2000).

\section{Novel potential motivation and utility for PCP and other psychomimetic-based investigations}

Acute PCP intoxication has been the most extensively used experimental preparation for antipsychotic drug development that focused on treating the positive symptoms of psychosis. As the drug development focus shifted from attenuating psychosis to cognition-promoting treatments, interest in the PCP model has waned; this was also due to the availability of more selective antagonist compounds and genetic models of potential etiological contributors to schizophrenia. Given the current interest in developing drugs that target cognitive symptoms in schizophrenia, the present demonstration of a set of PCP-induced cognition-related deficits indicates that the use of the PCP model could also be extended to the search for a procognitive antipsychotic (Moghaddam and Krystal, 2012). Indeed, recordings in prefrontal cortex under PCP and related NMDAR antagonist psychotomimetics indicate that the drugs discoordinate prefrontal network discharge and gamma oscillations (Wood et al., 2012), observations that the present findings extend to hippocampus and demonstrate with direct evidence of discoordinated neural representations of place and spatial information in the awake rat, as well as under anesthesia. Therefore, the relationship between PCP-induced discoordination in dorsal and ventral hippocampus and prefrontal cortex merits further study (Jodo et al., 2005; Jodo, 2013).

It is important to consider the dissociation between the novel PCP-induced cognitive control deficit (Fig. 2D) and the long-established hyperactivity that is thought to model the positive symptoms (Fig. 2C). Infusing PCP directly into the hippocampus impaired cognitive control measured by place avoidance (Fig. 2G) without causing hyperactivity (Fig. $2 F$ ) so long as the drug sufficiently increased medium-frequency gamma oscillations (Fig. $2 H)$. The dissociation could help us to understand why treatment
A
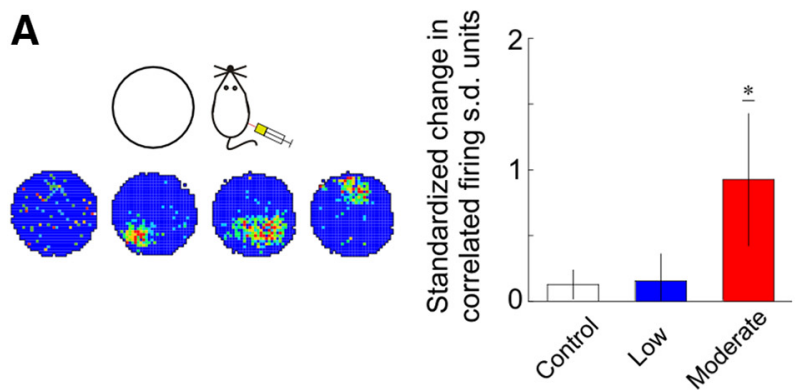

B

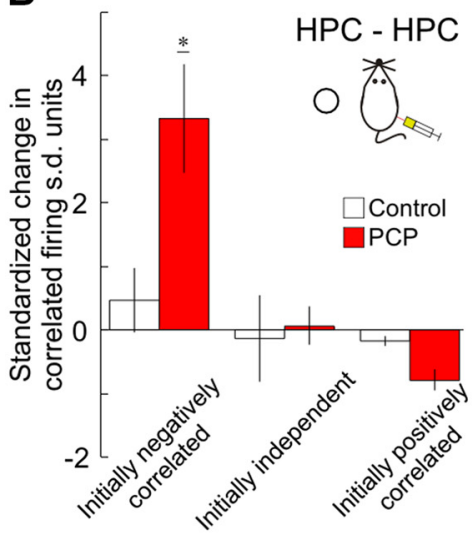

C *

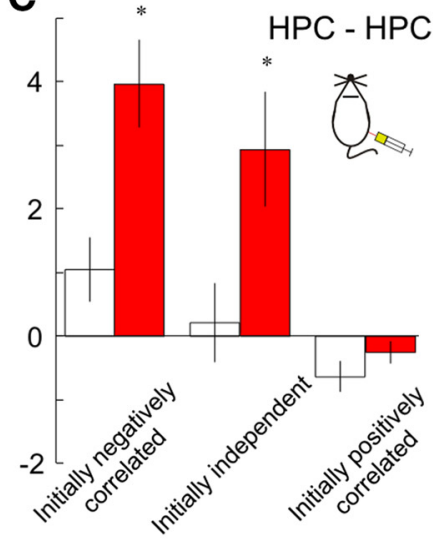

D mPFC - mPFC

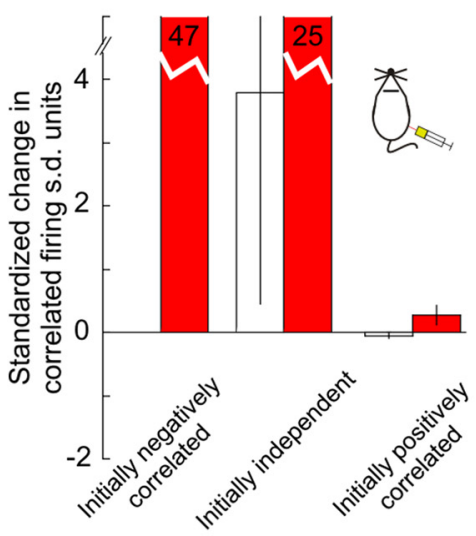

E

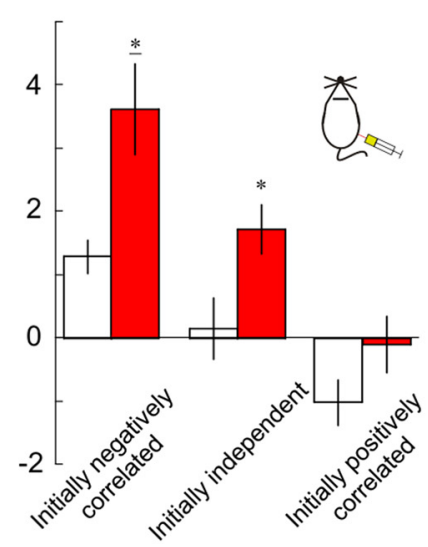

Figure 9. Systemic PCP alters neural coordination independently of hyperlocomotion. $A$, The change in Kendall's correlation $(\tau)$ from before to after PCP treatment was computed for all pairs of simultaneously recorded complex spike cells, not just place cells (four examples shown) as rats foraged in the cylinder. For each cell pair, spike counts were determined every $250 \mathrm{~ms}$ and the average correlation during the 65 min episodes was computed from the $30 \mathrm{~min}$ preinjection and postinjection recordings. Pre, Preinjection; control, low, moderate, $0,3,5 \mathrm{mg} / \mathrm{kg}$ PCP doses. ${ }^{*} p<0.05$ relative to control. $B, C, P C P$ changes the coupling of the cell pairs that are negatively correlated before injection, but not the cell pairs that were positively correlated before injection. The potential influence of location-specific place cell firing and $(6 \mathrm{mg} / \mathrm{kg}$, i.p.) PCP-induced hyperactivity was minimized by recording rats $(\boldsymbol{B})$ that were restricted to a $24 \mathrm{~cm}$ diameter circular enclosure with $20 \mathrm{~cm}$ high walls and by recording rats $(\boldsymbol{C}-\boldsymbol{E})$ under urethane anesthesia. The average and SD of these preinjection and postinjection episodes were computed for each cell pair. Cell pairs with significant negative or positive preinjection correlations were categorized as "initially negatively correlated" or "initially positively correlated" and those that were not significant correlated were categorized as "initially independent." Next, for each cell pair, we computed the standardized change of the correlation after each PCP dose. The standardization was done according to the following: (post - pre)/SD(pre), where pre and post indicate the average preinjection and postinjection correlations, respectively. This standardization was done to avoid the bias that can arise from estimating proportional changes in small numbers such as correlations near zero. The moderate dose of PCP selectively increased the coupling of only those cell pairs that were negatively or independently coupled before PCP administration without affecting the coupling of initially positively correlated cell pairs. Error bars indicate \pm SEM. Comparisons were made by ANOVA. ${ }^{*} p<0.05$ relative to the control; ${ }_{-} p<0.05$ relative to all other groups.

strategies that were developed by targeting hyperactivity and other sensorimotor abnormalities turned out to be inadequate for the cognitive symptoms (Carter and Barch, 2007). The present work also provides compelling evidence that, although 
A

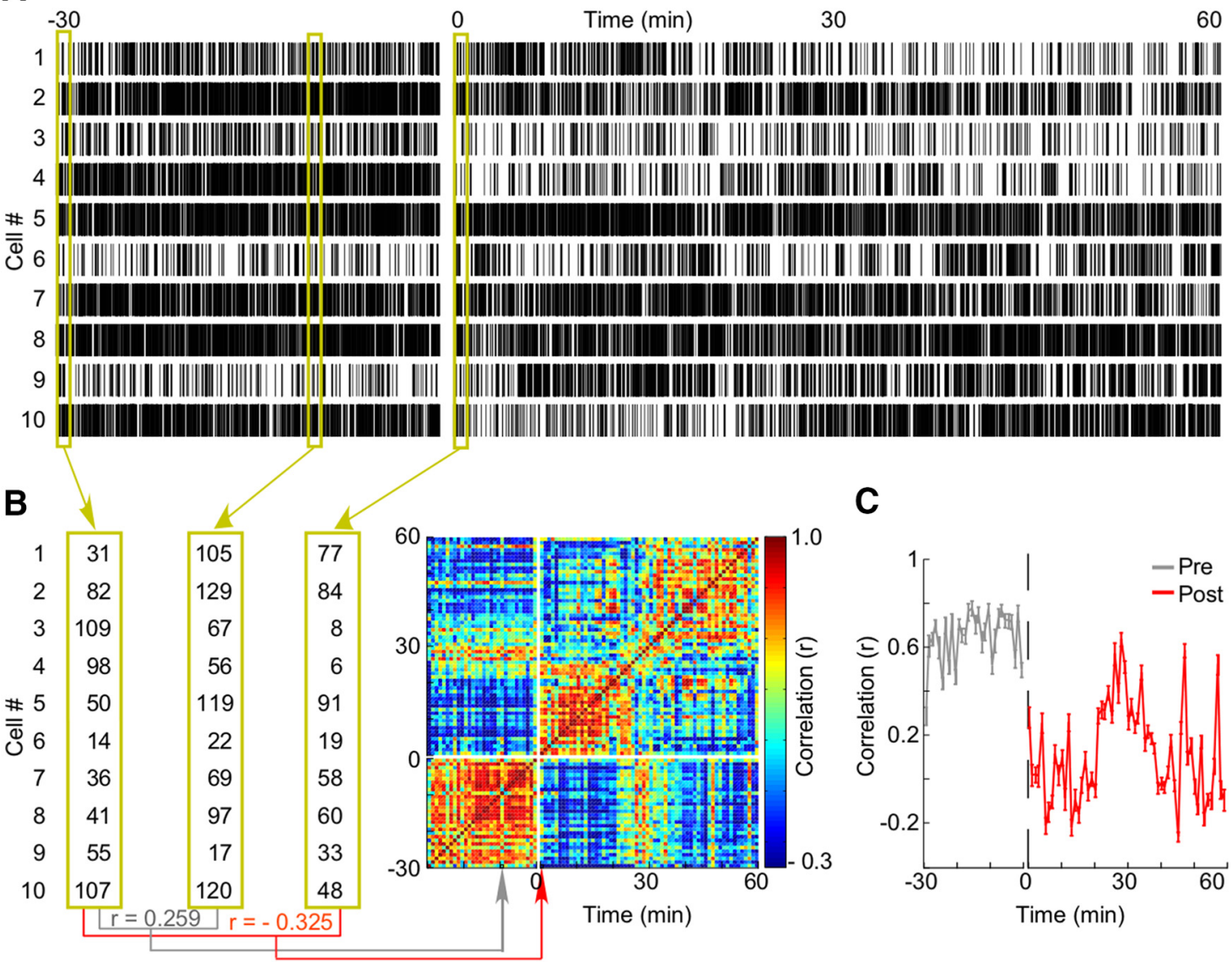

60

D

E

$\mathbf{F}$

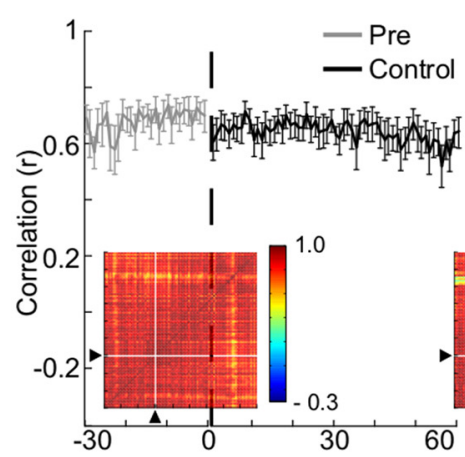

G

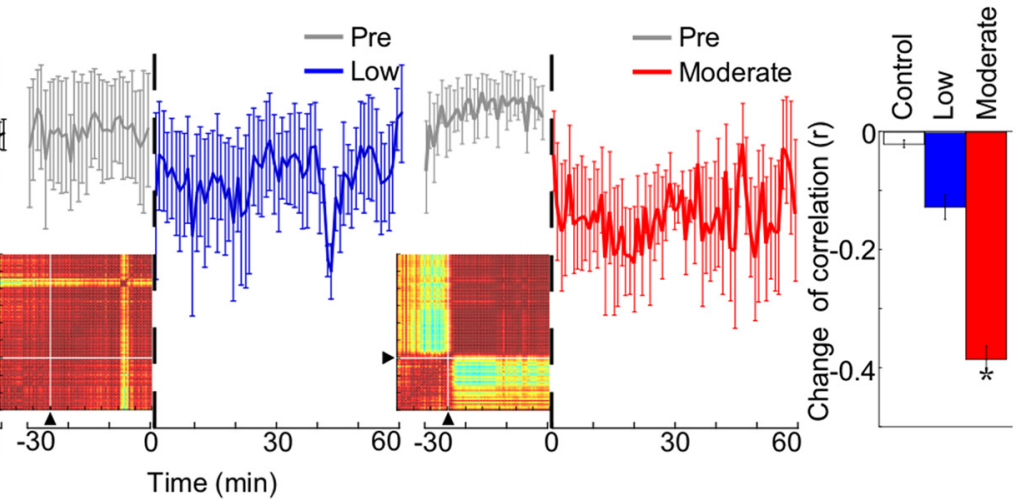

Figure 10. PCP-induced instability of multisecond timescale discharge coordination of place cells. $A$, Raster plots representing a 10-cell ensemble recording in which $5 \mathrm{mg} / \mathrm{kg} P C P$ was injected after 30 min at time $=0$. Ensemble activity vectors were computed each minute by summing the number of action potentials that each cell discharged during the minute. Three of these minute-long activity vectors are shown by yellow rectangles. B, Each activity vector was compared with every other activity vector using Pearson's correlation coefficient $(r)$ and the results are organized in the color-coded correlation matrix. C, Correlation was quantified by computing the average correlation between the current activity vector and all the preinjection vectors. The average \pm SEM of such correlations is shown for the different PCP doses: control $(n=12$ ensembles; $\boldsymbol{D})$, low $(n=4$ ensembles; $\boldsymbol{E})$, and moderate $(n=5$ ensembles; $\boldsymbol{F})$. $\boldsymbol{G}$, The average postinjection versus preinjection change in the correlation quantifies that the moderate dose of PCP changed the ensemble activity discharge pattern to a new pattern that did not resemble the hippocampal ensemble patterns before the injection. ${ }^{*} p<0.05$ relative to all groups.

NMDAR antagonism spares established memory, it can devastate the judicious use of information when sources of cognitive interference abound, such as during Room + Arena - place avoidance or initial place learning in the water maze (Bannerman et al., 1995; Saucier and Cain, 1995; Bannerman et al., 2006). These findings suggest that it may be fruitful to investigate cognitive control, in addition to learning and memory per se, in research directed at schizophrenia and other fields. Although these behav- ioral findings on their own suggest that acute PCP intoxication could with the right assays be exploited to model the core cognitive deficits in schizophrenia, the utility of the model lies in the theoretical importance of the findings. The electrophysiological findings provide unambiguous evidence that PCP discoordinates electrical neural activity between neurons (Figs. 6, 7, 8, 9, 10, 11) with minimal consequences on the response characteristics of individual cells (Tables 1, 2; Figs. 4, 5), as predicted by the disco- 
A
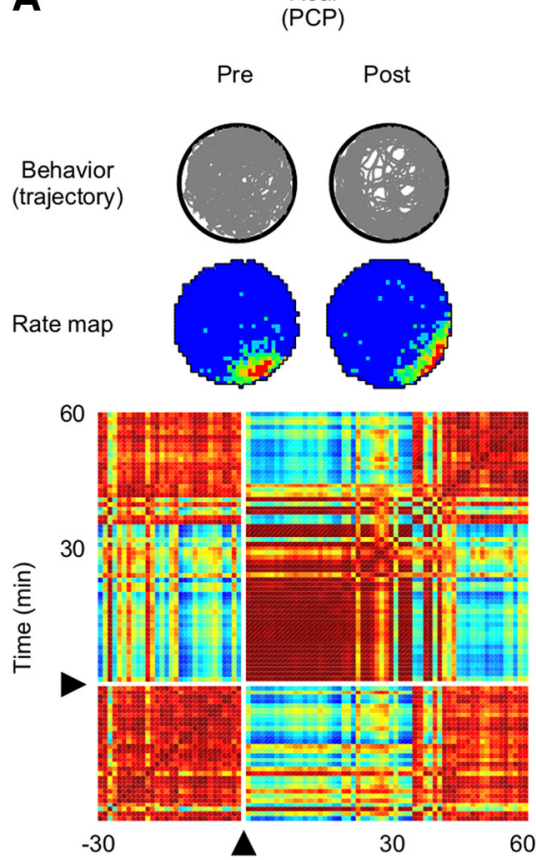

B

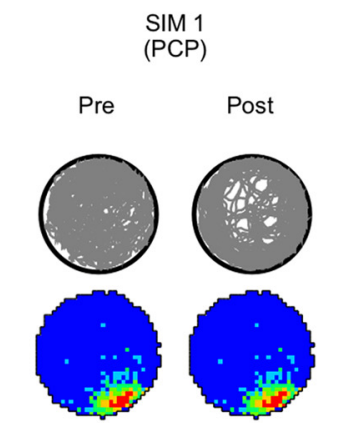

60

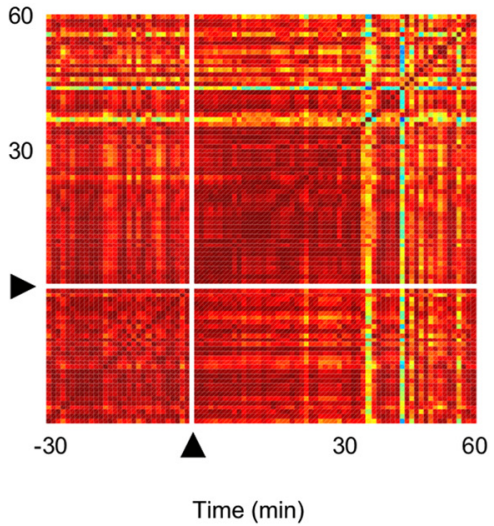

C SIM

(PCP)

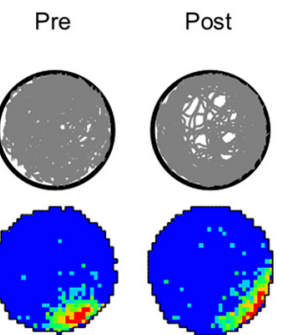

60

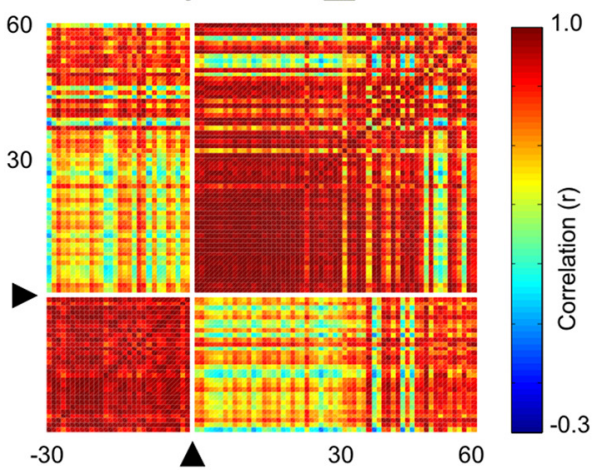

D

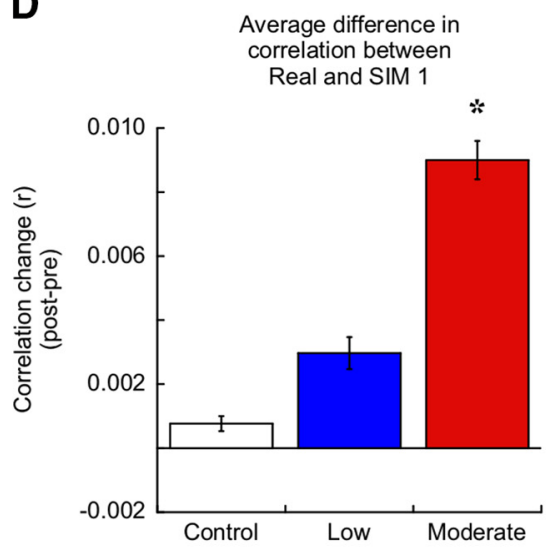

E

$$
\begin{gathered}
\text { Average difference in } \\
\text { correlation between } \\
\text { Real and SIM } 2
\end{gathered}
$$

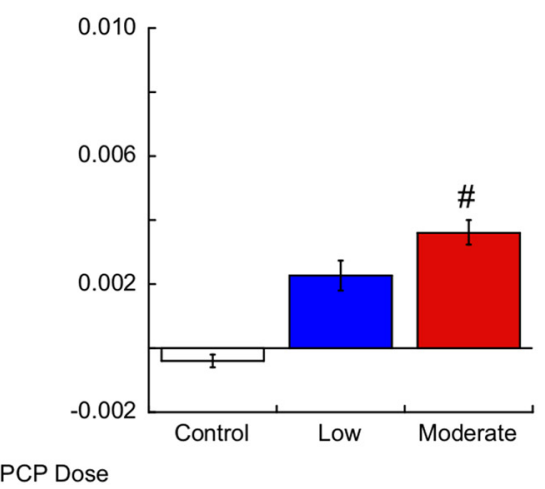

Figure 11. The PCP-induced neural discoordination is not explained by PCP-induced changes in motor behavior and subtle changes in firing rate maps. $A$, Real data showing the rat's trajectory during preinjection and postinjection sessions and example firing rate maps in preinjection and postinjection sessions. The correlation matrix that compares all pairs of ensemble activity vectors for an example recording is shown. In this "real" matrix, the moderate dose of PCP was injected at time $=0$. The change of ensemble activity pattern is manifested by decrease in correlation coefficients comparing preinjection and postinjection activity. The source of this change in activity was tested using two simulations. $\boldsymbol{B}$, Simulation 1 (SIM 1): the rat's trajectory and example firing rate map used in the simulation. The spike trains were simulated using an inhomogeneous Poisson model (Fenton et al., 2010) based on location-specific firing rate maps that were recorded before PCP injection and the actual spatial trajectory that the rat executed before and after PCP injection. The Poisson spike trains represent the location-specific discharge expected from the rat's particular behavior each minute, assuming that the location-specific firing rate map did not change after the PCP injection. The correlation matrix was created from simulated data. The change in ensemble activity, which is visible in real data, is not detected in the SIM 1 model, showing that change in the ensemble activity pattern cannot be accounted for by change in rat's motor behavior. C, Simulation 2 (SIM 2): the rat's trajectory and example firing rate maps used in the simulation. The spike trains were simulated based on the location-specific firing rate maps that were recorded before and after PCP injection and the actual spatial trajectory that the rat executed before and after PCP injection. The correlation matrix was created from simulated data. The change in ensemble activity after PCP injection in the SIM2 model is smaller than the change in activity observed in real data, showing that the change in ensemble activity pattern cannot be fully accounted for by the change in the rat's motor behavior and changes in firing rate maps. D, The average difference ( \pm SEM) in correlations between "real" and "SIM 1" correlation matrices after control, low, or moderate doses of PCP. The data compare the corresponding areas of the matrices that represent the postinjection activity vector correlations with the preinjection activity vectors. The effect of $P C P$ dose was significant $\left(F_{(2,18)}=13.17 ; p=2.99 \times 10^{-4}\right.$, ANOVA) because moderate PCP differed from both control and low dose of PCP (post hoc: control $=$ low $>$ moderate, $\left.p<0.004\right) . E$, Average difference ( \pm SEM) in correlations between "real" and "SIM 2" correlation matrices after control, low, or moderate doses of PCP. The data compare the corresponding areas of the matrices that represent the postinjection activity vector correlations with the preinjection activity vectors. The effect of PCP dose was significant $\left(F_{(2,18)}=5.14 ; p=0.171\right.$, ANOVA). Pre, Preinjection; Post, postinjection; control, low, moderate, $0,3,5 \mathrm{mg} / \mathrm{kg}$ PCP doses, respectively. ${ }^{*} p<0.05$ relative to all groups; $\# p<0.05$ relative to control group. 
ordination hypothesis. The findings that doses of PCP that impair cognitive behavior also discoordinate neural activity suggest that normalizing neural disccordination could be a procognitive therapeutic target. Although this may be accomplished by correcting a proximal cause of the dysfunction, procognitive effects can also be achieved by correcting the discoordination itself using pharmacological and/or neuromodulation treatment strategies to restore excitation-inhibition coordination or even by harnessing the plasticity that can accompany appropriate cognitive experience (Lee et al., 2012; Fenton, 2015).

\section{References}

Abi-Saab WM, D'Souza DC, Moghaddam B, Krystal JH (1998) The NMDA antagonist model for schizophrenia: promise and pitfalls. Pharmacopsychiatry 31:104-109. CrossRef Medline

Adams B, Moghaddam B (1998) Corticolimbic dopamine neurotransmission is temporally dissociated from the cognitive and locomotor effects of phencyclidine. J Neurosci 18:5545-5554. Medline

Anis NA, Berry SC, Burton NR, Lodge D (1983) The dissociative anaesthetics, ketamine and phencyclidine, selectively reduce excitation of central mammalian neurones by N-methyl-aspartate. Br J Pharmacol 79:565575. CrossRef Medline

Bannerman DM, Good MA, Butcher SP, Ramsay M, Morris RG (1995) Distinct components of spatial learning revealed by prior training and NMDA receptor blockade. Nature 378:182-186. CrossRef Medline

Bannerman DM, Rawlins JN, Good MA (2006) The drugs don't work-or do they? Pharmacological and transgenic studies of the contribution of NMDA and GluR-A-containing AMPA receptors to hippocampaldependent memory. Psychopharmacology (Berl) 188:552-566. CrossRef Medline

Bannerman DM, Bus T, Taylor A, Sanderson DJ, Schwarz I, Jensen V, Hvalby $\varnothing$, Rawlins JN, Seeburg PH, Sprengel R (2012) Dissecting spatial knowledge from spatial choice by hippocampal NMDA receptor deletion. Nat Neurosci 15:1153-1159. CrossRef Medline

Belluscio MA, Mizuseki K, Schmidt R, Kempter R, Buzsáki G (2012) Crossfrequency phase-phase coupling between theta and gamma oscillations in the hippocampus. J Neurosci 32:423-435. CrossRef Medline

Benardo LS (1995) N-methyl-D-aspartate transmission modulates GABABmediated inhibition of rat hippocampal pyramidal neurons in vitro. Neuroscience 68:637-643. CrossRef Medline

Bieri KW, Bobbitt KN, Colgin LL (2014) Slow and fast gamma rhythms coordinate different spatial coding modes in hippocampal place cells. Neuron 82:670-681. CrossRef Medline

Breier A, Malhotra AK, Pinals DA, Weisenfeld NI, Pickar D (1997) Association of ketamine-induced psychosis with focal activation of the prefrontal cortex in healthy volunteers. Am J Psychiatry 154:805-811. CrossRef Medline

Buzsáki G (2010) Neural syntax: cell assemblies, synapsembles, and readers. Neuron 68:362-385. CrossRef Medline

Caixeta FV, Cornélio AM, Scheffer-Teixeira R, Ribeiro S, Tort AB (2013) Ketamine alters oscillatory coupling in the hippocampus. Sci Rep 3:2348. CrossRef Medline

Canolty RT, Edwards E, Dalal SS, Soltani M, Nagarajan SS, Kirsch HE, Berger MS, Barbaro NM, Knight RT (2006) High gamma power is phaselocked to theta oscillations in human neocortex. Science 313:1626-1628. CrossRef Medline

Carter CS, Barch DM (2007) Cognitive neuroscience-based approaches to measuring and improving treatment effects on cognition in schizophrenia: the CNTRICS initiative. Schizophr Bull 33:1131-1137. CrossRef Medline

Cohen BD, Rosenbaum G, Luby ED, Gottlieb JS (1962) Comparison of phencyclidine hydrochloride (Sernyl) with other drugs. Simulation of schizophrenic performance with phencyclidine hydrochloride (Sernyl), lysergic acid diethylamide (LSD-25), and amobarbital (Amytal) sodium; II. Symbolic and sequential thinking. Arch Gen Psychiatry 6:395-401. CrossRef Medline

Colgin LL, Denninger T, Fyhn M, Hafting T, Bonnevie T, Jensen O, Moser MB, Moser EI (2009) Frequency of gamma oscillations routes flow of information in the hippocampus. Nature 462:353-357. CrossRef Medline

Dragoi G, Buzsáki G (2006) Temporal encoding of place sequences by hippocampal cell assemblies. Neuron 50:145-157. CrossRef Medline
Dragoi G, Tonegawa S (2011) Preplay of future place cell sequences by hippocampal cellular assemblies. Nature 469:397-401. CrossRef Medline

Dragoi G, Tonegawa S (2013) Distinct preplay of multiple novel spatial experiences in the rat. Proc Natl Acad Sci U S A 110:9100-9105. CrossRef Medline

Driesen NR, McCarthy G, Bhagwagar Z, Bloch MH, Calhoun VD, D'Souza DC, Gueorguieva R, He G, Leung HC, Ramani R, Anticevic A, Suckow RF, Morgan PT, Krystal JH (2013) The impact of NMDA receptor blockade on human working memory-related prefrontal function and connectivity. Neuropsychopharmacology 38:2613-2622. CrossRef Medline

Dvorak D, Fenton AA (2014) Toward a proper estimation of phaseamplitude coupling in neural oscillations. J Neurosci Methods 225:42-56. CrossRef Medline

Ehrlichman RS, Gandal MJ, Maxwell CR, Lazarewicz MT, Finkel LH, Contreras D, Turetsky BI, Siegel SJ (2009) N-methyl-d-aspartic acid receptor antagonist-induced frequency oscillations in mice recreate pattern of electrophysiological deficits in schizophrenia. Neuroscience 158:705712. CrossRef Medline

Ekstrom AD, Meltzer J, McNaughton BL, Barnes CA (2001) NMDA receptor antagonism blocks experience-dependent expansion of hippocampal "place fields". Neuron 31:631-638. CrossRef Medline

Fenton AA (2015) Excitation-inhibition discoordination in rodent models of mental disorders. Biol Psychiatry 77:1079-1088. CrossRef Medline

Fenton AA, Bures J (2003) Navigation in the moving world. In: The neurobiology of spatial behaviour (K. J. Jeffery, ed). Oxford: OUP.

Fenton AA, Muller RU (1998) Place cell discharge is extremely variable during individual passes of the rat through the firing field. Proc Natl Acad Sci U S A 95:3182-3187. CrossRef Medline

Fenton AA, Wesierska M, Kaminsky Y, Bures J (1998) Both here and there: simultaneous expression of autonomous spatial memories in rats. Proc Natl Acad Sci U S A 95:11493-11498. CrossRef Medline

Fenton AA, Kao HY, Neymotin SA, Olypher A, Vayntrub Y, Lytton WW, Ludvig N (2008) Unmasking the CA1 ensemble place code by exposures to small and large environments: more place cells and multiple, irregularly-arranged, and expanded place fields in the larger space. J Neurosci 28:11250-11262. CrossRef Medline

Fenton AA, Lytton WW, Barry JM, Lenck-Santini PP, Zinyuk LE, Kubík S, Bures J, Poucet B, Muller RU, Olypher AV (2010) Attention-like modulation of hippocampus place cell discharge. J Neurosci 30:4613-4625. CrossRef Medline

Fox SE, Ranck JB Jr (1975) Localization and anatomical identification of theta and complex spike cells in dorsal hippocampal formation of rats. Exp Neurol 49:299-313. CrossRef Medline

Fox SE, Wolfson S, Ranck JB Jr (1986) Hippocampal theta rhythm and the firing of neurons in walking and urethane anesthetized rats. Exp Brain Res 62:495-508. Medline

Fries P (2009) Neuronal gamma-band synchronization as a fundamental process in cortical computation. Annu Rev Neurosci 32:209-224. CrossRef Medline

Friston K, Buzsáki G (2016) The functional anatomy of time: what and when in the brain. Trends Cogn Sci 20:500-511. CrossRef Medline

Grunze HC, Rainnie DG, Hasselmo ME, Barkai E, Hearn EF, McCarley RW, Greene RW (1996) NMDA-dependent modulation of CA1 local circuit inhibition. J Neurosci 16:2034-2043. Medline

Harris KD, Csicsvari J, Hirase H, Dragoi G, Buzsáki G (2003) Organization of cell assemblies in the hippocampus. Nature 424:552-556. CrossRef Medline

Hebb DO (1949) The organization of behavior, a neuropsychological theory. New York: Wiley.

Hoffman RE (1997) Neural network simulations, cortical connectivity, and schizophrenic psychosis. MD Comput 14:200-208. Medline

Hoffman RE, McGlashan TH (2001) Neural network models of schizophrenia. Neuroscientist 7:441-454. CrossRef Medline

Holcomb HH, Lahti AC, Medoff DR, Cullen T, Tamminga CA (2005) Effects of noncompetitive NMDA receptor blockade on anterior cingulate cerebral blood flow in volunteers with schizophrenia. Neuropsychopharmacology 30:2275-2282. CrossRef Medline

Homayoun H, Moghaddam B (2007) NMDA receptor hypofunction produces opposite effects on prefrontal cortex interneurons and pyramidal neurons. J Neurosci 27:11496-11500. CrossRef Medline

Hong LE, Summerfelt A, Buchanan RW, O’Donnell P, Thaker GK, Weiler MA, Lahti AC (2010) Gamma and delta neural oscillations and associa- 
tion with clinical symptoms under subanesthetic ketamine. Neuropsychopharmacology 35:632-640. CrossRef Medline

Itil T, Keskiner A, Kiremitci N, Holden JM (1967) Effect of phencyclidine in chronic schizophrenics. Can Psychiatr Assoc J 12:209-212. CrossRef Medline

Itskov V, Pastalkova E, Mizuseki K, Buzsáki G, Harris KD (2008) Thetamediated dynamics of spatial information in hippocampus. J Neurosci 28:5959-5964. CrossRef Medline

Jackson J, Redish AD (2007) Network dynamics of hippocampal cellassemblies resemble multiple spatial maps within single tasks. Hippocampus 17:1209-1229. CrossRef Medline

Jodo E (2013) The role of the hippocampo-prefrontal cortex system in phencyclidine-induced psychosis: a model for schizophrenia. J Physiol Paris 107:434-440. CrossRef Medline

Jodo E, Suzuki Y, Katayama T, Hoshino KY, Takeuchi S, Niwa S, Kayama Y (2005) Activation of medial prefrontal cortex by phencyclidine is mediated via a hippocampo-prefrontal pathway. Cereb Cortex 15:663-669. CrossRef Medline

Keeley S, Fenton AA, Rinzel J (2016) Modeling fast and slow gamma oscillations with interneurons of different subtype. J Neurophysiol 117:950965. Medline

Kelemen E, Fenton AA (2010) Dynamic grouping of hippocampal neural activity during cognitive control of two spatial frames. PLoS Biol 8:e1000403. CrossRef Medline

Kelemen E, Fenton AA (2013) The organization of neuronal discharge on timescales of milliseconds and seconds is related to the spatial response properties of hippocampal neurons In: Advances in Cognitive Neurodynamics III (Y. Yamaguchi, ed.). Dordrecht, The Netherlands: Springer.

Kelemen E, Fenton AA (2016) Coordinating different representations in the hippocampus. Neurobiol Learn Mem 129:50-59. CrossRef Medline

Kentros CG, Agnihotri NT, Streater S, Hawkins RD, Kandel ER (2004) Increased attention to spatial context increases both place field stability and spatial memory. Neuron 42:283-295. CrossRef Medline

Kentros C, Hargreaves E, Hawkins RD, Kandel ER, Shapiro M, Muller RV (1998) Abolition of long-term stability of new hippocampal place cell maps by NMDA receptor blockade. Science 280:2121-2126. CrossRef Medline

Laughlin RB, Pines D, Schmalian J, Stojkovic BP, Wolynes P (2000) The middle way. Proc Natl Acad Sci U S A 97:32-37. CrossRef Medline

Lazarewicz MT, Ehrlichman RS, Maxwell CR, Gandal MJ, Finkel LH, Siegel SJ (2010) Ketamine modulates theta and gamma oscillations. J Cogn Neurosci 22:1452-1464. CrossRef Medline

Lee H, Dvorak D, Kao HY, Duffy ÁM, Scharfman HE, Fenton AA (2012) Early cognitive experience prevents adult deficits in a neurodevelopmental schizophrenia model. Neuron 75:714-724. CrossRef Medline

Lee H, Dvorak D, Fenton AA (2014) Targeting neural synchrony deficits is sufficient to improve cognition in a schizophrenia-related neurodevelopmental model. Front Psychiatry 5:15. CrossRef Medline

Lever C, Wills T, Cacucci F, Burgess N, O’Keefe J (2002) Long-term plasticity in hippocampal place-cell representation of environmental geometry. Nature 416:90-94. CrossRef Medline

Lodge D, Anis NA (1982) Effects of phencyclidine on excitatory amino acid activation of spinal interneurones in the cat. Eur J Pharmacol 77:203-204. CrossRef Medline

Ma J, Leung LS (2000) Relation between hippocampal gamma waves and behavioral disturbances induced by phencyclidine and methamphetamine. Behav Brain Res 111:1-11. CrossRef Medline

Maurer AP, Vanrhoads SR, Sutherland GR, Lipa P, McNaughton BL (2005) Self-motion and the origin of differential spatial scaling along the septotemporal axis of the hippocampus. Hippocampus 15:841-852. CrossRef Medline

Moghaddam B, Adams BW (1998) Reversal of phencyclidine effects by a group II metabotropic glutamate receptor agonist in rats. Science 281: 1349-1352. CrossRef Medline

Moghaddam B, Krystal JH (2012) Capturing the angel in "angel dust": twenty years of translational neuroscience studies of NMDA receptor antagonists in animals and humans. Schizophr Bull 38:942-949. CrossRef Medline

Moghaddam B, Adams B, Verma A, Daly D (1997) Activation of glutamatergic neurotransmission by ketamine: a novel step in the pathway from NMDA receptor blockade to dopaminergic and cognitive disruptions associated with the prefrontal cortex. J Neurosci 17:2921-2927. Medline
Molina LA, Skelin I, Gruber AJ (2014) Acute NMDA receptor antagonism disrupts synchronization of action potential firing in rat prefrontal cortex. PLoS One 9:e85842. CrossRef Medline

Morris RG, Anderson E, Lynch GS, Baudry M (1986) Selective impairment of learning and blockade of long-term potentiation by an N-methyl-Daspartate receptor antagonist, AP5. Nature 319:774-776. CrossRef Medline

Muller RU, Kubie JL (1989) The firing of hippocampal place cells predicts the future position of freely moving rats. J Neurosci 9:4101-4110. Medline

Muller RU, Kubie JL, Ranck JB Jr (1987) Spatial firing patterns of hippocampal complex spike cells in a fixed environment. J Neurosci 7:19351950. Medline

Murray JD, Anticevic A, Gancsos M, Ichinose M, Corlett PR, Krystal JH, Wang XJ (2014) Linking microcircuit dysfunction to cognitive impairment: effects of disinhibition associated with schizophrenia in a cortical working memory model. Cereb Cortex 24:859-872. CrossRef Medline

Neymotin SA, Lytton WW, Olypher AV, Fenton AA (2011) Measuring the quality of neuronal identification in ensemble recordings. J Neurosci 31: 16398-16409. CrossRef Medline

Neymotin SA, Talbot ZN, Jung JQ, Fenton AA, Lytton WW (2017) Tracking recurrence of correlation structure in neuronal recordings. J Neurosci Methods 275:1-9. CrossRef Medline

Olypher AV, Lánský P, Fenton AA (2002) Properties of the extra-positional signal in hippocampal place cell discharge derived from the overdispersion in location-specific firing. Neuroscience 111:553-566. CrossRef Medline

Olypher AV, Lánský P, Muller RU, Fenton AA (2003) Quantifying locationspecific information in the discharge of rat hippocampal place cells. J Neurosci Methods 127:123-135. CrossRef Medline

Olypher AV, Klement D, Fenton AA (2006) Cognitive disorganization in hippocampus: a physiological model of the disorganization in psychosis. J Neurosci 26:158-168. CrossRef Medline

O'Reilly KC, Kao HY, Lee H, Fenton AA (2014) Converging on a core cognitive deficit: the impact of various neurodevelopment insults on cognitive control. Front Neurosci 8.

O’Reilly KC, Perica MI, Fenton AA (2016) Memory deficits with intact cognitive control in the methylazoxymethanol acetate (MAM) exposure model of neurodevelopmental insult. Neurobiol Learn Mem 134:294303. CrossRef Medline

Park E, Dvorak D, Fenton AA (2011) Ensemble place codes in hippocampus: CA1, CA3, and dentate gyrus place cells have multiple place fields in large environments. PLoS One 6:e22349. CrossRef Medline

Pastalkova E, Serrano P, Pinkhasova D, Wallace E, Fenton AA, Sacktor TC (2006) Storage of spatial information by the maintenance mechanism of LTP. Science 313:1141-1144. CrossRef Medline

Phillips WA, Silverstein SM (2003) Convergence of biological and psychological perspectives on cognitive coordination in schizophrenia. Behav Brain Sci 26:65-82; discussion 82-137. Medline

Press WH, Flannery BP, Teukolsky SA, Vetterling WT (1993) Numerical recipes in C: the art of scientific computing, Ed 2. Cambridge: Cambridge University.

Radwan B, Dvorak D, Fenton AA (2016) Impaired cognitive discrimination and discoordination of coupled theta-gamma oscillations in Fmrl knockout mice. Neurobiol Dis 88:125-138. CrossRef Medline

Ranck JB Jr (1973) Studies on single neurons in dorsal hippocampal formation and septum in unrestrained rats. I. Behavioral correlates and firing repertoires. Exp Neurol 41:461-531. Medline

Rowland LM, Bustillo JR, Mullins PG, Jung RE, Lenroot R, Landgraf E, Barrow R, Yeo R, Lauriello J, Brooks WM (2005) Effects of ketamine on anterior cingulate glutamate metabolism in healthy humans: a 4-T proton MRS study. Am J Psychiatry 162:394-396. CrossRef Medline

Saucier D, Cain DP (1995) Spatial learning without NMDA receptor-dependent long-term potentiation. Nature 378:186-189. CrossRef Medline

Schneidman E, Berry MJ 2nd, Segev R, Bialek W (2006) Weak pairwise correlations imply strongly correlated network states in a neural population. Nature 440:1007-1012. CrossRef Medline

Schomburg EW, Anastassiou CA, Buzsáki G, Koch C (2012) The spiking component of oscillatory extracellular potentials in the rat hippocampus. J Neurosci 32:11798-11811. CrossRef Medline

Schomburg EW, Fernández-Ruiz A, Mizuseki K, Berényi A, Anastassiou CA, Koch C, Buzsáki G (2014) Theta phase segregation of input-specific 
gamma patterns in entorhinal-hippocampal networks. Neuron 84:470485. CrossRef Medline

Seeman P, Ko F, Tallerico T (2005) Dopamine receptor contribution to the action of PCP, LSD and ketamine psychotomimetics. Mol Psychiatry 10: 877-883. CrossRef Medline

Sershen H, Balla A, Aspromonte JM, Xie S, Cooper TB, Javitt DC (2008) Characterization of interactions between phencyclidine and amphetamine in rodent prefrontal cortex and striatum: implications in NMDA/ glycine-site-mediated dopaminergic dysregulation and dopamine transporter function. Neurochem Int 52:119-129. CrossRef Medline

Skaggs WE, McNaughton BL, Gothard KM, Markus EJ (1993) An information theoretic approach to deciphering the hippocampal code. In: Advances in neural information processing (Hanson SJ, Cowan JD, Giles CL, eds), pp 1030-1037. San Mateo, CA: Morgan Kaufmann.

Szczurowska E, Ahuja N, Jiruška P, Kelemen E, Stuchlík A (2018) Impairment of neural coordination in hippocampal neuronal ensembles after a psychotomimetic dose of dizocilpine. Prog Neuropsychopharmacol Biol Psychiatry. 81:275-283. CrossRef Medline

Tononi G, Edelman GM (2000) Schizophrenia and the mechanisms of conscious integration. Brain Res Brain Res Rev 31:391-400. CrossRef Medline

Tort AB, Komorowski RW, Manns JR, Kopell NJ, Eichenbaum H (2009) Theta-gamma coupling increases during the learning of item-context associations. Proc Natl Acad Sci U S A 106:20942-20947. CrossRef Medline

Uhlhaas PJ, Singer W (2006) Neural synchrony in brain disorders: relevance for cognitive dysfunctions and pathophysiology. Neuron 52:155-168. CrossRef Medline

Vollenweider FX, Leenders KL, Scharfetter C, Antonini A, Maguire P, Missimer J, Angst J (1997) Metabolic hyperfrontality and psychopathology in the ketamine model of psychosis using positron emission tomography (PET) and [18F] fluorodeoxyglucose (FDG). Eur Neuropsychopharmacol 7:9-24. CrossRef Medline

Wesierska M, Dockery C, Fenton AA (2005) Beyond memory, navigation, and inhibition: behavioral evidence for hippocampus-dependent $\operatorname{cog}$ nitive coordination in the rat. J Neurosci 25:2413-2419. CrossRef Medline

Wills TJ, Lever C, Cacucci F, Burgess N, O’Keefe J (2005) Attractor dynamics in the hippocampal representation of the local environment. Science 308:873-876. CrossRef Medline

Wood J, Kim Y, Moghaddam B (2012) Disruption of prefrontal cortex large scale neuronal activity by different classes of psychotomimetic drugs. J Neurosci 32:3022-3031. CrossRef Medline

Zhang K, Ginzburg I, McNaughton BL, Sejnowski TJ (1998) Interpreting neuronal population activity by reconstruction: unified framework with application to hippocampal place cells. J Neurophysiol 79:1017-1044. Medline

Ziv Y, Burns LD, Cocker ED, Hamel EO, Ghosh KK, Kitch LJ, El Gamal A, Schnitzer MJ (2013) Long-term dynamics of CA1 hippocampal place codes. Nat Neurosci 16:264-266. CrossRef Medline 